\title{
Biomass-derived nanostructured porous carbons for lithium-sulfur batteries
}

\author{
Sumair Imtiaz ${ }^{1 \dagger}$, Jian Zhang ${ }^{2 \dagger}$, Zahid Ali Zafar ${ }^{1}$, Shengnan $\mathrm{Ji}^{1}$, Taizhong Huang ${ }^{1}$, \\ James A. Anderson ${ }^{3}$, Zhaoliang Zhang ${ }^{1 *}$ and Yunhui Huang ${ }^{2 *}$
}

\begin{abstract}
Biomass has been utilized as an energy source for thousands of years typically in the form of wood and charcoal. Technological advances create new methodologies to extract energy and chemicals from biomass. The biomass-derived nanostructured porous carbons (BDNPCs) are the most promising sulfur hosts and interlayers in rechargeable lithium-sulfur (Li-S) batteries. In this article, a comprehensive review is provided in the synthesis of nanostructured porous carbon materials for high-performance rechargeable Li-S batteries by using biomass. The performances of the $\mathrm{Li}-\mathrm{S}$ batteries dependent on the porous structures (micro, meso and hierarchical) from BDNPCs are discussed, which can provide an in-depth understanding and guide rational design of high-performance cathode materials by using low-cost, sustainable and natural bio-precursors. Furthermore, the current existing challenges and the future research directions for enhancing the performance of $\mathrm{Li}-\mathrm{S}$ batteries by using natural biomass materials are also addressed.
\end{abstract}

Keywords: biomass, lithium-sulfur battery, porous carbon, cathode, sulfur hosts, interlayers

\section{INTRODUCTION}

Carbon is an essential constituent of the universe and all living organisms, which is the 4 th most abundant element in the universe and the 2nd most common element in human body with a percentage of $18.5 \%$ by mass [1]. It has many forms or allotropes, which are widely used in many fields. Among them, porous carbon has been well developed and extensively utilized in modern industrial society due to its porous microstructure with immense surface area [2-4], high porosity along with good physiochemical sta- bility [5,6], large adsorption capacity [7] and excellent reactivity [8-10]. However, the fabrication of such porous carbon faces some challenges as it is a complex and expensive synthesis process, involving high temperature and non-renewable precursors consequently limiting its commercial applications. Therefore, the importance of finding facile and cost-effective routes for obtaining porous carbon is a high priority. Due to the fact that naturally available materials have hierarchically nano-structures with inorganic/organic composites, the derivation of functional materials from naturally available resources has always been very attractive for academic researchers and industrial applications in order to obtain environmentally friendly materials with facile techniques [11]. For example, biomass-derived nanostructured porous carbons (BDNPCs) have been used in many applications such as adsorbents, $\mathrm{CO}_{2}$ storage, catalytic supports or catalysts $[12,13]$. Very recently, they have also been widely employed in the energy storage devices such as rechargeable lithium-sulfur (Li-S) battery.

Li-S battery is one of the most promising candidates to satisfy commercialized electrochemical power storage sources due to its high theoretical capacity and energy density of $1,675 \mathrm{~mA} \mathrm{~h} \mathrm{~g}^{-1}$ and $2,500 \mathrm{~W} \mathrm{~h} \mathrm{~kg}^{-1}$, respectively. However, Li-S batteries suffer many issues including low sulfur utilization, poor long-term cycling stability, large volumetric expansion and low columbic efficiency, as detailed in next section, which has greatly limited their practical use. Various attempts have been made to overcome the above mentioned problems such as the use of

${ }^{1}$ School of Chemistry and Chemical Engineering, Shandong Provincial Key Laboratory of Fluorine Chemistry and Chemical Materials, University of Jinan, Jinan 250022, China

${ }^{2}$ State Key Laboratory of Material Processing and Die \& Mould Technology, School of Materials Science and Engineering, Huazhong University of Science and Technology, Wuhan 430074, China

${ }^{3}$ Surface Chemistry and Catalysis Group, Materials and Chemical Engineering, School of Engineering, University of Aberdeen, Aberdeen AB24 3UE, UK

The first two authors contributed equally to this work.

* Corresponding authors (emails: chm_zhangzl@ujn.edu.cn (Zhang Z); huangyh@hust.edu.cn (Huang Y)) 
composites of sulfur with graphene or graphene oxide [14-16], carbon nanotubes/nanowires/nanofibers and porous carbons $[6,15,17-19]$. Among various materials, porous carbons have attained most considerable attention due to their porous structure and high conductivity, large surface area, pore volume and strong adsorption ability in attempts to overcome the problems associated with Li-S batteries. As mentioned above, BDSPCs have also been well developed with an aim at overcoming these challenges. The use of BDSPCs plays a key role in the enhancement of performance of Li-S batteries.

In this mini review, biomass-derived nanostructured porous carbons for Li-S batteries are summarized and prospected. General synthetic methods for nanostructured porous carbon are presented. By analyzing the working principles and the current challenges for Li-S batteries especially with regard to sulfur cathodes, a detailed and comprehensive overview of advances involving utilization of BDSPCs in Li-S batteries in recent years and the influence of porous structure of BDSPCs on the battery performance are discussed. Furthermore, current challenges and approaches are introduced for addressing the shortages from the perspective of the use of natural biomass materials as precursors.

\section{PRINCIPLE AND FUNDAMENTALS OF}

\section{LI-S BATTERIES}

For Li-S batteries, the electrodes consist of a lithium metal anode and a sulfur cathode, which are separated by a separator filled with electrolyte $[15,20]$. Sulfur has a theoretical specific capacity of $1675 \mathrm{~mA} \mathrm{~h} \mathrm{~g}^{-1}$. The average voltage of the Li-S cell is $2.15 \mathrm{~V}$ with a theoretical energy density of $2500 \mathrm{~W} \mathrm{~h} \mathrm{Kg}^{-1}$ or $2800 \mathrm{~W} \mathrm{~h} \mathrm{~L}^{-1}$ [21,22]. Fig. 1 shows a schematic configuration of a typical Li-S cell. The electrical energy is stored/released through a reversible redox reaction during charge/discharge operation [20]. The reaction starts from discharge, because sulfur is in a charged state [15]. On discharge, the Li metal at the anode is oxidized to produce Li ions and electrons. The Li ions and electrons produced travel to the cathode via the electrolyte and through the external circuit, respectively. As a result, sulfur is converted to lithium sulfide. The reverse reaction occurs during the charging process. The anode and cathode reactions are expressed as follows [21]:

$$
\begin{gathered}
16 \mathrm{Li} \rightarrow 16 \mathrm{Li}^{+}+16 \mathrm{e}^{-} \text {(anode reaction) } \\
\mathrm{S}_{8}+16 \mathrm{Li}^{+}+16 \mathrm{e}^{-} \rightarrow 8 \mathrm{Li}_{2} \mathrm{~S} \text { (cathode reaction) }
\end{gathered}
$$

It is widely accepted that the discharge of $\mathrm{S}$ proceeds through multiple steps $[20,21,23]$ :

$$
\begin{gathered}
\mathrm{S}_{8}+2 \mathrm{Li}^{+}+2 \mathrm{e}^{-} \rightarrow \mathrm{Li}_{2} \mathrm{~S}_{8} \\
3 \mathrm{Li}_{2} \mathrm{~S}_{8}+2 \mathrm{Li}^{+}+2 \mathrm{e}^{-} \rightarrow 4 \mathrm{Li}_{2} \mathrm{~S}_{6} \\
2 \mathrm{Li}_{2} \mathrm{~S}_{6}+2 \mathrm{Li}^{+}+2 \mathrm{e}^{-} \rightarrow 3 \mathrm{Li}_{2} \mathrm{~S}_{4} \\
\mathrm{Li}_{2} \mathrm{~S}_{4}+2 \mathrm{Li}^{+}+2 \mathrm{e}^{-} \rightarrow 2 \mathrm{Li}_{2} \mathrm{~S}_{2} \\
\mathrm{Li}_{2} \mathrm{~S}_{2}+2 \mathrm{Li}^{+}+2 \mathrm{e}^{-} \rightarrow 2 \mathrm{Li}_{2} \mathrm{~S}
\end{gathered}
$$

A typical charge/discharge profile in a Li-S cell is illustrated in Fig. 1 [22]. Two voltage plateaus at 2.4 and $2.0 \mathrm{~V}$ during discharge correspond to the reduction of long chain and short chain polysulfides, respectively. During the charge cycle, two plateaus at 2.2 and $2.5 \mathrm{~V}$ are observed. The five steps of the discharge procedure can be divided into two parts [24,25]. The initial three steps which occur at high voltage plateaus exhibit fast reaction kinetics, corresponding to the formation of long chain lithium polysulfides $\left(\mathrm{Li}_{2} \mathrm{~S}_{x}, x \geq 4\right)$ which are readily dissolved in the liquid electrolyte. In the latter two steps (low and long voltage plateaus), insoluble $\mathrm{Li}$ polysulfides $\left(\mathrm{Li}_{2} \mathrm{~S}_{x}\right.$, $x \leq 4)$ are formed which precipitate out at the cathode. The kinetics of the latter two steps are much slower due to liquid $\mathrm{Li}_{2} \mathrm{~S}_{4} /$ solid $\mathrm{Li}_{2} \mathrm{~S}_{2}$ and solid $\mathrm{Li}_{2} \mathrm{~S}_{2} / \mathrm{Li}_{2} \mathrm{~S}$ interfaces, and the conversion from $\mathrm{Li}_{2} \mathrm{~S}_{2}$ to $\mathrm{Li}_{2} \mathrm{~S}$ is difficult due to the sluggish kinetics as a result of the solid-state reactions [20-23,26,27].

Despite the considerable advantages for the Li-S cell, there are also many challenges. Of these, the first one is the

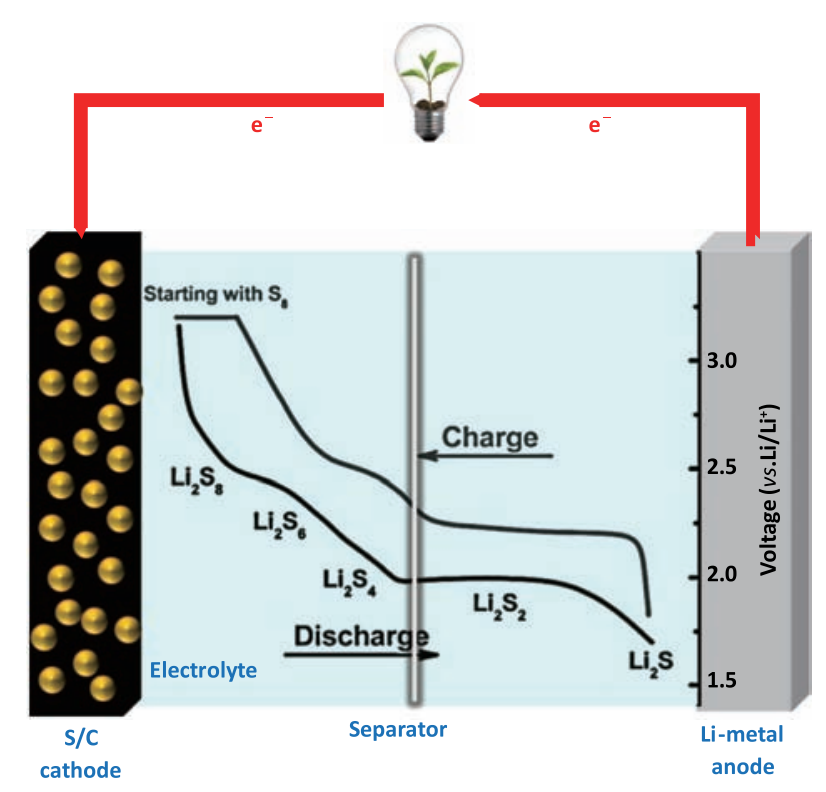

Figure 1 Schematic configuration, typical charge/discharge profile and chemistry of sulfur cathode in a traditional liquid Li-S cell. 
poor intrinsic conductivity of sulfur $\left(5 \times 10^{-30} \mathrm{~S} \mathrm{~cm}^{-1}\right)$ [27] and the insulating nature of $\mathrm{Li}_{2} \mathrm{~S}$, which results in low utilization of the active material and gives rise to limited rate capability. The second one is the volumetric change which occurs during the charge/discharge process. Due to the difference between the densities of sulfur $\left(2.03 \mathrm{~g} \mathrm{~cm}^{-3}\right)$ and $\mathrm{Li}_{2} \mathrm{~S}\left(1.66 \mathrm{~g} \mathrm{~cm}^{-3}\right)$, the volume changes by up to $80 \%$ during the conversion between sulfur and $\mathrm{Li}_{2} \mathrm{~S}$ [21]. This large volume change may deteriorate the architecture of electrode, leading to the degradation of the active material, and hence to poor mechanical stability and severe capacity fade. Thirdly, the high-order polysulfides are soluble in the electrolyte. These dissolved polysulfide anions can freely be transported between the anode and cathode, which is the so-called shuttle effect $[15,21]$. The high-order polysulfides diffuse to the surface of the $\mathrm{Li}$ anode and are reduced to insoluble low-order polysulfides. Then these low-order polysulfides return to the cathode and are oxidized to high-order polysulfides. This results in the loss of active material, self-discharge behavior, passivation of the Li-metal surface with insoluble product, and an increase in impedance and decrease in columbic efficiency $[20,21,27,28]$.

To address these issues, developing sulfur/carbon composite cathodes with sulfur embedded into the conductive carbon frameworks has been proven as one of the most promising perspectives over the past decade for improving the performance of Li-S batteries. By creating composites of sulfur with carbon, the poor conductive properties of sulfur can be constrained within the carbon frameworks resulting in great enhancement of the conductivity of the sulfur electrode, and the solubility losses of the intermediate sulfur species in the liquid electrolyte can be restrained owing to the excellent sorption properties of the carbon. Both factors lead to a much improved electrochemical performance of Li-S batteries. Although numerous nanoporous carbon-based materials, including carbon nanospheres, carbon nanotubes, graphene nanosheets, etc., show good performance in Li-S batteries, most of these require a complex synthesis process, using expensive and non-renewable precursors. Fortunately, many biomass materials in the nature can be efficiently transformed into various nanostructured porous carbons. The preparation and cost of these BDSPCs are much easier and cheaper than the above-mentioned nanoporous carbon-based materials. Numerous literatures have reported the use of BDSPCs in Li-S batteries as sulfur host materials that exhibit excellent electrochemical properties. In the coming sections, the synthesis strategy of nanostructured porous carbon is introduced, and the advance made by using low-cost and eco-friendly biomass materials in Li-S batteries to achieve high utilization of active material, good cycling stability, high columbic efficiency and large power density is presented.

\section{SYNTHESIS OF NANOSTRUCTURED POROUS CARBONS FROM BIOMASS}

Biomass from agricultural crop residues, forest crops and other renewable resources could be converted into nanostructured porous carbons with high surface area and pore volume by well-developed facile methods [29]. Thermochemical conversion technologies, such as pyrolysis or hydrothermal carbonization (HTC) are widely used to derive carbon from biomass. In pyrolysis, the biomass is thermo-chemically degraded at elevated temperatures, normally in the range of $300-650^{\circ} \mathrm{C}$ under inert atmosphere whereas the HTC converts the biomass into carbon by utilizing water as a carbonization medium in a milder temperature range $\left(180-260^{\circ} \mathrm{C}\right)$ under autogenic pressure [30-36]. HTC is advantageous because of the relatively high yields of carbonaceous solids and the elimination of energy intensive pre-drying [32]. However, both pyrolysis and HTC cannot fulfill all of the required properties of nanostructured porous carbons because they produce materials with limited surface area and porosity [37]. In general, high surface area, large pore volume and well defined pore size distribution are the key parameters to obtain excellent electrochemical performance in $\mathrm{Li}-\mathrm{S}$ batteries. Hence, many researchers have implanted the nano-template into the biomass precursor before the pyrolysis, followed by removal of template, which can generally be denoted as sacrificial template method (STM) $[29,30]$. Compared to the direct pyrolysis or HTC, the STM prepared carbon not only owns a higher surface area, but also has a well-uniformed pore size distribution determined by the parameter of the sacrificial template. Nevertheless, to achieve the best required battery performance, the carbon obtained from the above-mentioned method must be subjected to an activation process that can further tune the carbon structure and morphology $[37,38]$.

The tuning of pore size distribution and surface area after pyrolysis or HTC of biomass is carried out by physical or chemical activation. In physical or thermal activation, the pyrolyzed carbon is exposed to an oxidizing atmosphere (such as $\mathrm{CO}_{2}$, steam or a mixture of both) in the temperature range of $600-1200^{\circ} \mathrm{C}$ and the porosity is developed by partial etching of the carbon. On the other hand, in chemical activation the carbon precursor is mixed with some chemicals such as $\mathrm{NaOH}$ [39], $\mathrm{KOH}$ [40-48], $\mathrm{ZnCl}_{2}$ 
[5,49-51], $\mathrm{H}_{3} \mathrm{PO}_{4}$ [52-54] and $\mathrm{H}_{2} \mathrm{SO}_{4}[3,55]$, and then carbonization and activation are accomplished simultaneously at a slightly lower temperature ranged within $300-950^{\circ} \mathrm{C}$. Of the activating agents, $\mathrm{KOH}$ is the most promising because it can produce nanostructured porous carbons with higher yields at lower temperature, and produce materials with ultrahigh specific surface area up to $3000 \mathrm{~m}^{2} \mathrm{~g}^{-1}$ with a well-defined pore size distribution. The activation by $\mathrm{KOH}$ is a convoluted process and involves many chemical reactions. Generally, the reaction between $\mathrm{KOH}$ and carbon commences as solid-solid reaction and proceeds through solid-liquid reactions [56,57]. Marsh et al. [58] described the activation by $\mathrm{KOH}$ and suggested that two main processes lead to the chemical activation. In the first process, the alkali metal act as a catalyst and carbon is consumed by oxygen, and as a result $\mathrm{CO}$ and $\mathrm{CO}_{2}$ is produced. In the second process, hydroxide is reduced to give free potassium metal, and this free metal penetrates into the carbon lattice. As a result of this penetration carbon lattice is expanded and the speedy removal of free metal from carbon occurs. Otowa et al. [57] described the $\mathrm{KOH}$ activation of petroleum coke by various simultaneous/consecutive reactions. They proposed that below $700^{\circ} \mathrm{C} \mathrm{H}_{2} \mathrm{O}, \mathrm{H}_{2}, \mathrm{CO}$, $\mathrm{CO}_{2}, \mathrm{~K}_{2} \mathrm{O}$ and $\mathrm{K}_{2} \mathrm{CO}_{3}$ were the main products and above $700^{\circ} \mathrm{C}$ the formation of metallic potassium and activation process occurs (Fig. 2). Thus, the carbon activated by $\mathrm{KOH}$ shows high surface area and porosity due to the synergetic effect of physical and chemical activation, and intercalation of metallic K into the carbon lattice [38]. The degree of activation can be controlled by two parameters: the amount of $\mathrm{KOH}$ and the activation temperature [59]. However, the reactivity of the various carbon sources along with these activation parameters also play significant role in determining the pore structure and surface chemistry. In general, lower surface area and pore volume are obtained with higher precarbonization temperature whereas high $\mathrm{KOH} /$ Carbon ratio and activation temperature result in high porosity [38]. Despite the fact that both physical and chemical activation can produce carbons with a porous network, chemical acti- vation has the advantage over physical activation because it produces nanostructured porous carbons at lower temperature, shorter time, with a higher surface area and a more uniform pore size distribution [12,13,29,33,37,38,60-66].

\section{BIO-DERIVED CARBON AS SULFUR HOST IN Li-S BATTERIES}

The bio-derived carbons are of much interest due to low cost, high availability and good product yield of the biosources. These sources can be synthesized to green, energy efficient and cost effective carbons. Bio-carbon with particular categories of shapes and pores can be obtained by employing modern carbonization techniques. Moreover, considering the fact that surface chemistry is important especially for Li-S batteries, inherent doped carbon can also be produced from these cheap resources. The carbons produced from bio-sources have high surface area and pore volume which when employed in energy storage devices, showed excellent electrochemical properties. The carbons obtained from biomass which are applied as sulfur hosts in Li-S batteries, can be divided into microporous, mesoporous, hierarchically porous and other nanostructured carbons according to the structure of the carbon obtained. In the following sections, the important progress in such carbon materials as sulfur hosts in Li-S batteries is summarized.

\section{Bio-derived microporous carbon}

According to the International Union of Pure and Applied Chemistry (IUPAC), a microporous carbon contains pores with size less than $2 \mathrm{~nm}$ [20]. The sulfur composite with microporous carbon is a good choice to immobilize the sulfur and to avoid polysulfide dissolution [18]. Although many works have been done on S/microporous carbon composites, researchers continue to show much interest in utilizing bio-derived carbons in Li-S batteries due to their facile synthesis, low cost and high availability and sustainability.

$\mathrm{Gu}$ et al. [67] used bamboo-derived carbon as host of sulfur for Li-S battery. They activated the bamboo carbon
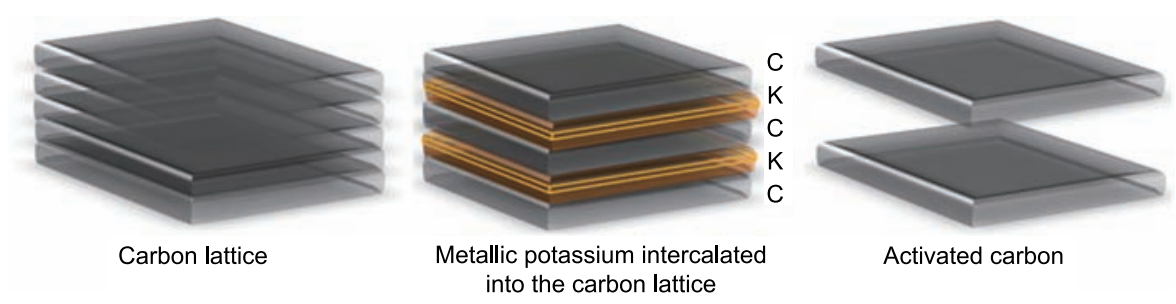

Figure 2 The activation process above $700^{\circ} \mathrm{C}$, intercalation of carbon lattice by metallic $\mathrm{K}$, expansion of carbon lattice and rapid removal of intercalated metallic K from the carbon matrix. Reprinted with permission from Ref. [59], Copyright 2012, Institute of Physics. 
with $\mathrm{KOH}$ and annealed it at $700^{\circ} \mathrm{C}$ to create microporous structure which enhanced the surface area by up to 14 times and pore volume to almost 8 times. The sulfur was infiltrated into the treated carbon to achieve the $\mathrm{S} /$ bamboo carbon composites with S loadings of 40, 50 and 60 wt.\%. Excellent electrochemical properties, such as high initial capacity (1295 $\left.\mathrm{mA} \mathrm{h} \mathrm{g}^{-1}\right)$ and Columbic efficiency ( $\left.\geq 95 \%\right)$ were attained in the sample with $50 \mathrm{wt} . \% \mathrm{~S}$ loading. Yang et al. [68] employed a facile and bio-inspired safe technique to synthesize activated carbons with a high product yield of $40.7 \mathrm{wt}$ \% from waste apricot shells. The apricot shell was firstly pyrolyzed at $750^{\circ} \mathrm{C}$ and then mixed with $\mathrm{KOH}$ and heated at $750^{\circ} \mathrm{C}$ to obtain activated porous carbon. The obtained porous carbon showed large pore volume $\left(1.05 \mathrm{~cm}^{3}\right.$ $\left.\mathrm{g}^{-1}\right)$ and surface area $\left(2269 \mathrm{~m}^{2} \mathrm{~g}^{-1}\right)$ with irregular particles that were widely distributed from several up to tens of micrometers. The sulfur was infiltrated into the porous carbon through capillary action and the pore size distribution $(0.6-2.0 \mathrm{~nm})$ of the as-prepared porous carbon allowed sulfur to be loaded in a highly dispersed state. The obtained S/porous carbon composite showed excellent electrochemical performance due to the different pore sizes and partially graphitized structure. It was able to effectively inhibit the shuttle of polysulfides, enhance the conductivity and facilitate gain or loss of electrons. Its discharge capacity was as high as $613 \mathrm{~mA} \mathrm{~h} \mathrm{~g}^{-1}$ after 200 cycles at $1 \mathrm{C}$.

It has been stated that the microporous carbon can confine only small sulfur molecules due to the space limitation and hence the formation of soluble polysulfides can be avoided. However, there are still some questions regarding this hypothesis since no solid evidence has been reported till now [69]. Helen et al. [70] demonstrated the direct transformation of sulfur to smaller sulfur molecules $\left(\mathrm{Li}_{2} \mathrm{~S}_{2} / \mathrm{Li}_{2} \mathrm{~S}\right)$ by using ultra-microporous carbon (Fig. 3) as sulfur host and carbonate-based electrolyte. Coconut shell derived ultra-microporous carbon was synthesized by carbonization at $600^{\circ} \mathrm{C}$ with $\mathrm{KOH}$ as activating agent. The S/ultra-microporous carbon composite with 45.8 wt.\% S loading was obtained by vacuum assisted melt-diffusion. The lithiation/delithiation and capacity fading mechanism of the composite was analyzed by using X-ray photoelectron spectroscopy (XPS) sputter profiling, which demonstrated the direct transformation from $\mathrm{S}$ to $\mathrm{Li}_{2} \mathrm{~S}_{2} / \mathrm{Li}_{2} \mathrm{~S}$ during cycling. Since there is no direct contact between $\mathrm{S}$ and the liquid electrolyte, the reaction is of quasi solid-state and thus $\mathrm{S}$ can be directly transformed to $\mathrm{Li}_{2} \mathrm{~S}_{2} / \mathrm{Li}_{2} \mathrm{~S}$. The capacity fade in the composite can be ascribed to the encapsulated sulfur within the narrow pores of ultra-microporous carbon and discharge products. The absence of higher

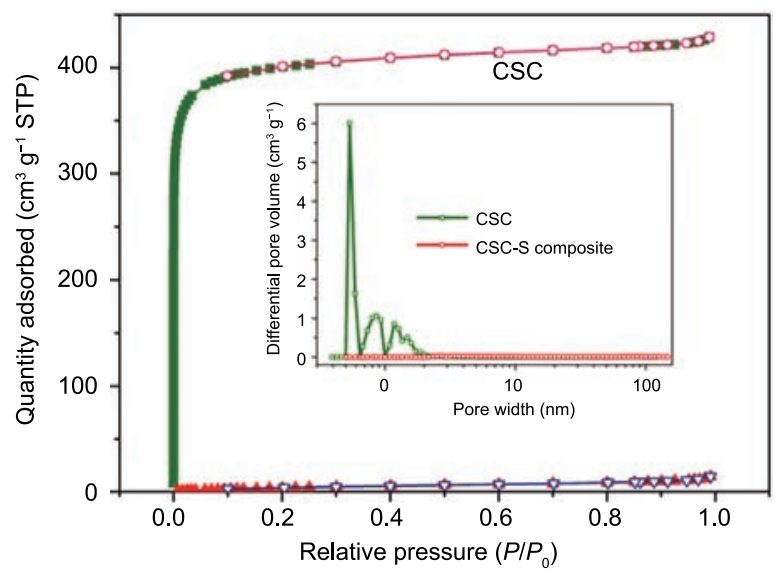

Figure $3 \mathrm{~N}_{2}$ adsorption/desorption isotherm for coconut shell derived ultra-microporous carbon (CSC) and CSC-S composite. Inset shows the distribution of pore size. Reprinted with permission from Ref. [70], Copyright 2015, Nature Publishing Group.

polysulfides in the electrolyte, on the surface and in the subsurface of the composite gives rise to a sustainable cycling performance of over 400 Cycles with Columbic efficiency of $99.6 \%$.

In addition to the tuning of pore sizes and volume, the surface chemistry of porous carbon materials is also very important for Li-S batteries. Since the carbon is non-polar whereas Li polysulfides are inherently polar molecules, the cathodes which make up this non-polar host still face fast capacity decay over long-term cycling because it can only permit adsorption of polysulfides up to diffusion limitations $[71,72]$. Surface properties of the porous carbon can be altered by functionalization such as doping with $\mathrm{N}$ or B. Doping carbon with N or B is an effective way to enhance the intrinsic properties of porous carbon materials as it may facilitate the chemisorption of Li polysulfides at the surface [16,73-76]. By considering the fact that N-doping can improve the performance of Li-S batteries, Yu et al. [77] synthesized an inherently N-doped microporous carbon from human hair by carbonization and $\mathrm{NaOH}$ activation at $900^{\circ} \mathrm{C}$ (Fig. 4). XPS showed that inherent doping of $\mathrm{N}$ significantly changed the electrical properties and provided additional adsorption sites for Li polysulfides. The S/C composite with 69 wt.\% S loading showed Columbic efficiency higher than $98.6 \%$ for 200 cycles at 0.2 C. Further wrapping this composite with reduced graphene oxide provided considerably improved electrochemical properties with a high reversible capacity of $989 \mathrm{~mA} \mathrm{~h} \mathrm{~g}^{-1}$ and a Columbic efficiency of $99.8 \%$ after 300 cycles. The superior performance of cathode was attributed to the porous structure of carbon with inherent $\mathrm{N}$-doping and graphene 


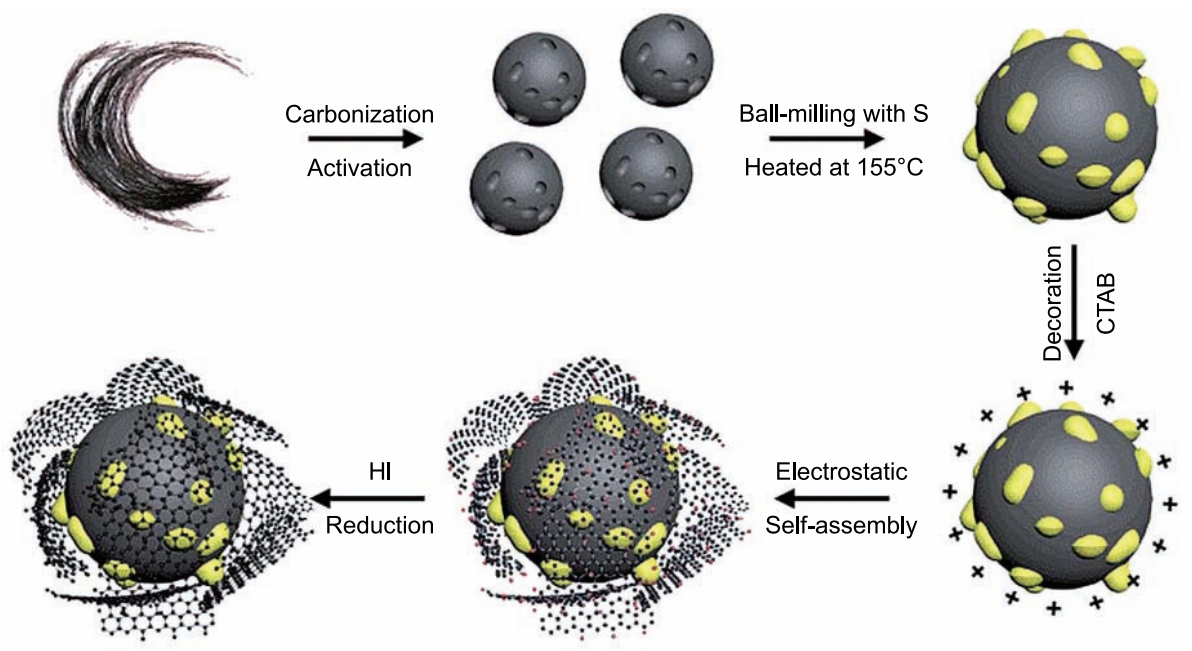

Figure 4 Schematic illustration of the hair derived carbon, and g-C/S composite preparation process. Reprinted with permission from Ref. [77], Copyright 2015, Royal Society of Chemistry.

\section{protection.}

Some characteristics of the microporous carbons derived from biomass and the resulting properties obtained for Li-S batteries are summarized in Table 1. The microporous $\mathrm{C} / \mathrm{S}$ composites exhibit unprecedented electrochemical behavior because of the smaller sulfur entities, $S_{2-4}$, as starting material. Thus, the higher order polysulfides are not formed during the reaction and the shuttle effect can be avoided. As an outcome, excellent cycling stability, high rate capability and electrolyte compatibility are obtained.

\section{Bio-derived mesoporous carbon}

Mesoporous carbon with a pore diameter between 2 and 50 $\mathrm{nm}$ has reasonable pore volume, which can permit high $\mathrm{S}$ loading and improve ionic/electronic and electrolyte transportation $[78,79]$. Pioneering work on the use of mesoporous carbon in Li-S batteries was performed by Nazar's group in 2009 [79], in which high S loading and large initial capacity were attained. Subsequently, many researchers have developed low-cost bio-derived mesoporous carbons instead of the commercially-available mesoporous carbon to achieve high-performance Li-S batteries.

The direct pyrolysis of naturally derived biomass materials can efficiently be used to prepare the mesoporous carbons. For example, Cheng et al. [80] utilized bamboo charcoal as a sulfur host and attained $57.7 \mathrm{wt} . \% \mathrm{~S}$ loading by a melt-diffusion technique. The charcoal with pore size of about $4 \mathrm{~nm}$ exhibited a surface area of $57.8 \mathrm{~m}^{2} \mathrm{~g}^{-1}$ and pore volume of $0.05 \mathrm{~cm}^{3} \mathrm{~g}^{-1}$. They obtained a very stable composite with the reversible capacity of $414 \mathrm{~mA} \mathrm{~h} \mathrm{~g}^{-1}$ after 500 cycles at $0.5 \mathrm{C}$. A mesoporous carbon microtube was prepared by pyrolysis of poplar catkins at $800^{\circ} \mathrm{C}$ by Zhang et al. [81] and employed as a sulfur host in Li-S batteries. The carbon microtubes showed a Brunauer-Emmett-Teller (BET) surface area of $186 \mathrm{~m}^{2} \mathrm{~g}^{-1}$ and a pore volume of 0.287 $\mathrm{cm}^{3} \mathrm{~g}^{-1}$. At $0.1 \mathrm{C}$, after 100 cycles the composite delivered reversible capacity of $810 \mathrm{~mA} \mathrm{~h} \mathrm{~g}^{-1}$ and initial discharge capacity of $1173 \mathrm{~mA} \mathrm{~h} \mathrm{~g}^{-1}$. The excellent electrochemical properties of the composite were due to the mesoporous surface that provided good electrical conductivity and trapped the polysulfides intermediates. However, the carbon prepared by this method has limited surface area and pore volume, which cannot fulfill the requirements of Li-S batteries with high energy density.

To improve the surface area and pore volume, the use of biomass material along with STM can develop outstanding mesoporous carbons. Brun et al. [82] prepared the carbon material from biomass via an environmentally friendly and cost effective HTC route. They used glucose and xylose as carbon precursors and nanosized silica spheres as hard templates to obtain hollow carbon spheres (HCS). The as-prepared HCS showed an average shell thickness of 5-8 nm. The glucose-derived HCS had a smaller surface area and thicker carbon walls as compared to the xylose-derived one. Sulfur was encapsulated into the HCS by melt-diffusion method and the composites were examined as electrode for Li-S batteries. The same group also synthesized $\mathrm{N}$-doped carbon aerogels (NCA) by catalyst-free hydrothermal treatment from glucose, $D$-glucosamine and/or $N$-acetyl- $D$-glucosamine and phenolic compounds [83]. They applied the obtained NCA as metal-free oxygen reduction catalyst. Followed their own work, Brun et al. 
Table 1 Microporous, mesoporous and hierarchical porous carbons derived from biomass used as electrode materials and their properties for Li-S batteries

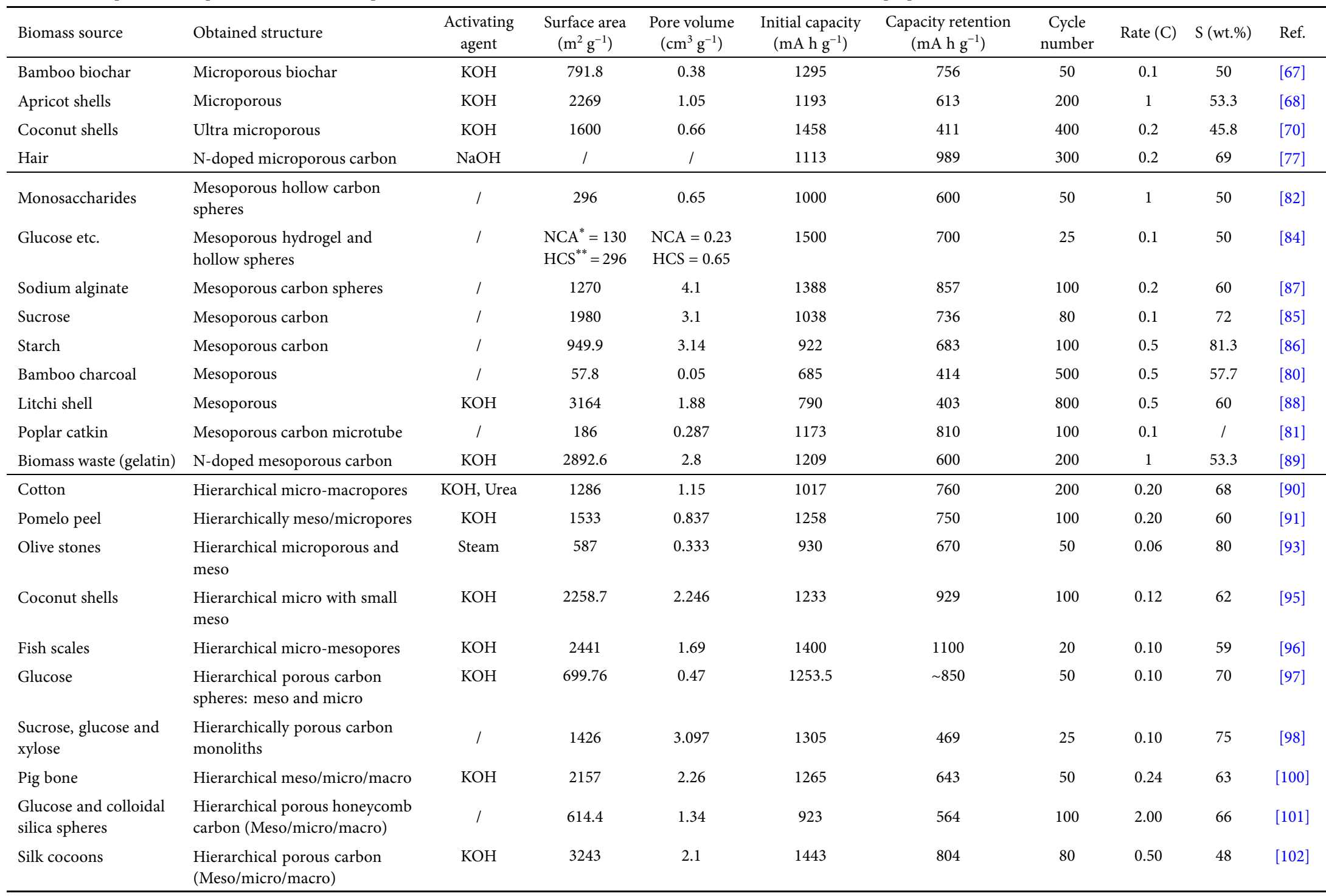

* N-doped carbon aerogels, ** Hollow carbon spheres 
[84] studied the synergistic effect of carbohydrate derived HCS and NCA for improving performance in Li-S battery. Compared with the previously-reported results of HCS/S [82], the S composite with mixed NCA and HCS exhibited a surprisingly higher specific capacity of more than 700 $\mathrm{mA} \mathrm{h} \mathrm{g}{ }^{-1}$ with a low capacity fading over 25 cycles.

Based on the reactive carbochlorination etching of $\mathrm{TiO}_{2}$ nanoparticles inside dense carbon matrix, Kaskel's group prepared a type of highly mesoporous carbon material called Kroll-carbons by using sucrose as a carbon precursor [85]. The Kroll carbon with a specific surface area of $1980 \mathrm{~m}^{2} \mathrm{~g}^{-1}$ and pore volume of $3.1 \mathrm{~cm}^{3} \mathrm{~g}^{-1}$ showed high performance as a sulfur host with initial specific capacity of approximately $1400 \mathrm{~mA} \mathrm{~h} \mathrm{~g}^{-1}$. Li et al. [86] reported a facile, chemical activation-free method to prepare highly porous carbon derived from starch and colloidal silica as templates through sol-gel method. The as-synthesized porous carbons contained uniform mesopores with a large pore volume of $3.14 \mathrm{~cm}^{3} \mathrm{~g}^{-1}$ and a surface area of 949.85 $\mathrm{m}^{2} \mathrm{~g}^{-1}$. Sulfur was infiltrated by melting-infusion and a very high S loading (81.3 wt.\%) was achieved. At $0.5 \mathrm{C}$, the composite exhibited an initial capacity of $922 \mathrm{~mA} \mathrm{~h} \mathrm{~g}^{-1}$ and a high reversible capacity of $483 \mathrm{~mA} \mathrm{~h} \mathrm{~g}^{-1}$ was still maintained after 300 cycles at $1 \mathrm{C}$. They suggested that these excellent electrochemical properties of the sulfur cathode were due to the uniform and appropriate structure of porous carbons. Sodium alginate (a biopolymer from seaweed) was subjected to carbonization at $900^{\circ} \mathrm{C}$ for $5 \mathrm{~h}$ with colloidal silica as pore directing template and produced mesoporous carbon spheres with hierarchical pores (3-30 $\mathrm{nm})$ [87]. Carbon spheres with surface area of $1270 \mathrm{~m}^{2} \mathrm{~g}^{-1}$ and pore volume of $4.1 \mathrm{~cm}^{3} \mathrm{~g}^{-1}$ were obtained by tuning the ratio of sodium alginate and pore directing agent. Sulfur was infiltrated by a one-step autogenetic high-pressure method, and Li-S cell based on this composite maintained a capacity of $857 \mathrm{~mA} \mathrm{~h} \mathrm{~g}^{-1}$ after 100 cycles at $0.2 \mathrm{C}$.

As mentioned above, the $\mathrm{KOH}$ activated porous carbon has ultrahigh specific surface area with excellent porous structure. Zhang et al. [88] utilized waste litchi shells as precursor along with $\mathrm{KOH}$ activation at $900^{\circ} \mathrm{C}$ to prepare porous carbon. The nature of channel-like macropores in waste litchi shells can be efficiently introduced with $\mathrm{KOH}$ into the internal channel, which is beneficial to activation and creation of more porosity with high surface area. The synthesized activated porous carbon owned a large pore volume of $1.88 \mathrm{~cm}^{3} \mathrm{~g}^{-1}$ and ultrahigh surface area of 3164 $\mathrm{m}^{2} \mathrm{~g}^{-1}$. The carbon was employed as host matrix for sulfur and the composite was fabricated by simple melt-diffusion process with $60 \mathrm{wt} . \% \mathrm{~S}$ loading. The high surface area and pore volume of carbon ensured the fine dispersion and high content of sulfur in a conducting network. Due to the excellent structural parameters of litchi-derived porous carbon, very promising electrochemical results were obtained. The available nanopores effectively suppressed the dissolution of polysulfides. An initial discharge capacity of 1105

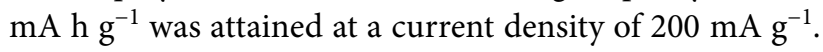
At $800 \mathrm{~mA} \mathrm{~g}^{-1}$, the composite showed long-term capacity retention of $51 \%$ after 800 cycles.

In addition, based on the reports that $\mathrm{N}$-doping could further improve the electrochemical properties via enhanced surface affinity to Li polysulfides [16,73,74,76], $\mathrm{Qu}$ et al. [89] synthesized ordered N-rich mesoporous carbon by pyrolysis of gelatin (biomass waste) as a carbon source and SBA-15 as hard template. The N-rich mesoporous carbon was activated with $\mathrm{KOH}$ and the surface area increased to $2892.6 \mathrm{~m}^{2} \mathrm{~g}^{-1}$ with a pore volume of 2.80 $\mathrm{cm}^{3} \mathrm{~g}^{-1}$. The obtained carbon showed acceptable $\mathrm{S}$ loading (53.3 wt.\%) and a stable framework to sustain the volume expansion and suppress the shuttle phenomenon. Due to the increased surface adsorption via $\mathrm{N}$-doping (9.74 at.\%), the diffusion of polysulfides was further inhibited. The composite exhibited stable cycling performance and high rate capability, as it maintained the discharge capacity of $600 \mathrm{~mA} \mathrm{~h} \mathrm{~g}^{-1}$ after 200 cycles at $1 \mathrm{C}$.

Various bio-derived mesoporous carbons and their corresponding properties used as hosts in Li-S batteries are summarized in Table 1. The large pore volume with high $S$ loading makes the mesoporous carbons excellent contenders as hosts for Li-S batteries. The mesoporous carbons not only facilitate sulfur encapsulation but also improve the ionic/electronic and electrolyte transportation as well as an increase in voltage plateau. However, due to the large pore size compared to microporous carbons, they cannot avoid the dissolution of polysulfides. The modified surface of mesoporous carbon with nitrogen assists in avoiding the shuttling effect because N-doping provides enhanced chemical adsorption and increases the electronic conductivity of carbon. A coating of conducting polymer on the surface of mesoporous carbon/sulfur composite can also provide improved performance by limiting the transport of polysulfides within the carbon matrix.

\section{Bio-derived hierarchical porous carbon}

In order to obtain high performance in Li-S batteries, a carbon material is required to provide a suitably high pore volume for a high $S$ loading, suppress the shuttle effect, ensure good electrolyte penetration and facilitate electronic/ionic transport. According to the previous studies, an individ- 
ual material such as macro-, meso- or microporous carbon cannot fulfill all of these requirements for a sulfur host. Therefore, by accepting the advantage of each category of pores, consistent efforts have been made in an attempt to fabricate hierarchical porous carbons (HPC). HPCs contain at least two categories of pores, which take the advantages of micro-, meso- and macro-pores. Combining the benefits of different categories of pores to load sulfur is an alternative methodology to achieve better performance for Li-S batteries [78].

Bimodal porous carbon can provide dual advantage of pores. Bimodal mesoporous carbon has many advantages to achieve high performance Li-S batteries without sacrificing capacity and cycle life. Wang et al. [90] presented a simple approach for synthesizing micro/macro-porous carbon with cotton as a carbon source. Chemical activation was carried out by using $\mathrm{KOH}$. Two samples were studied: one treated with $\mathrm{KOH} /$ urea and the other with $\mathrm{KOH}$ alone. They found that the former treatment of carbon led to only micropores, but the later produced a material featuring micro-macropores. The micro/macro-porous carbon displayed a surface area of $1286 \mathrm{~m}^{2} \mathrm{~g}^{-1}$. A simple heating method was employed to infiltrate the sulfur into the as-prepared carbon and attained an S loading of 68 wt.\%. The composite exhibited an excellent electrochemical performance in which micropores adequately trapped the polysulfides whereas macropores enhanced the efficient transportation of electrons/ions and electrolyte. A good rate capability and a large capacity of $760 \mathrm{~mA} \mathrm{~h} \mathrm{~g}^{-1}$ at $0.2 \mathrm{C}$ after 200 cycles were obtained.

Previously prepared activated carbon featured a pore size distribution ranging from micro to macropores, and due to limited electronic contact of sulfur within the macropores, significant polarization could occur. To overcome these issues, Zhang et al. [91] prepared a 3D carbon material from pomelo peels by $\mathrm{KOH}$ assisted carbonization at $600^{\circ} \mathrm{C}$. They synthesized a highly porous carbon foam (mirco/meso porosity) with a surface area and pore volume of $1533 \mathrm{~m}^{2} \mathrm{~g}^{-1}$ and $0.837 \mathrm{~cm}^{3} \mathrm{~g}^{-1}$, respectively. The obtained carbon foam was applied as binder-free and freestanding support for a sulfur electrode. The sulfur was loaded up to $60.1 \mathrm{wt} . \%$ via a solution approach to fabricate the S/carbon foam. Due to the 3D structure of the carbon foam, the initial discharge capacity of $1258 \mathrm{~mA} \mathrm{~h} \mathrm{~g}^{-1}$ at $0.2 \mathrm{C}$ and Columbic efficiency of $96 \%$ were attained. Olive stone, a by-product of olive oil production, was used as a carbon precursor to synthesize activated carbon at $700^{\circ} \mathrm{C}$ under steam activation [92-94]. Moreno et al. [93] used the obtained carbon with the surface area of $587 \mathrm{~m}^{2} \mathrm{~g}^{-1}$ and pore volume of $0.333 \mathrm{~cm}^{3} \mathrm{~g}^{-1}$ as sulfur host. The investigation on pore size distribution indicated the availability of micro and mesopores. The activated carbon/S composite was fabricated by in situ deposition and a high sulfur loading of $80 \%$ was obtained. The microporous texture of the activated carbon adequately trapped the polysulfides during the redox reaction. On cycling, the composite showed excellent capacity retention and delivered a capacity of $670 \mathrm{~mA} \mathrm{~h} \mathrm{~g}^{-1}$. Coconut-shells were utilized by Liu et al. [95] to synthesize a carbon structure with micropores and a low number of mesopores (average pore size of $2.246 \mathrm{~nm}$ ). After loading with $62 \mathrm{wt} . \%$ sulfur, the material gave a retained discharge capacity of $929 \mathrm{~mA} \mathrm{~h} \mathrm{~g}^{-1}$ after 100 cycles at $0.12 \mathrm{C}$. Following recent interest in using cost-effective approaches, Zhao et al. [96] employed fish scales to synthesize bimodal porous carbon mainly containing micro and mesopores. The fish scales were activated with $\mathrm{KOH}$ and calcined at $900^{\circ} \mathrm{C}$. The as-prepared carbon had a very high surface area of $2441 \mathrm{~m}^{2} \mathrm{~g}^{-1}$ and a pore volume of $1.69 \mathrm{~cm}^{3} \mathrm{~g}^{-1}$. The composite displayed various benefits such as high active site density due to high surface area, accommodation of volume expansion, suppression of shuttle effect and conductive path for Li ions. As a consequence of the benefits of hierarchically structure, the cathode showed high initial discharge capacity of $1039 \mathrm{~mA} \mathrm{~h} \mathrm{~g}^{-1}$ at $1 \mathrm{C}$ and excellent cycling stability of $1023 \mathrm{~mA} \mathrm{~h} \mathrm{~g}^{-1}$ after 70 cycles.

A variety of monosaccharide and disaccharides have been utilized as green carbon precursors for many years. By applying modern carbonization techniques, high quality carbon materials with special categories of pores and shapes can be obtained $[6,82,84,85,97-99]$. Porous carbon spheres were developed by Park et al. [97] using glucose as the carbon precursor and $\mathrm{KOH}$ as the activating agent. The 3D interconnected micro and mesoporous carbon spheres provided a large surface area and a porosity which allowed sulfur to be stored in the mesopores and on the surface of carbon spheres. Compared with the porous carbon hosts, the shape of porous carbon spheres provided the advantage of featuring enhanced packing density of electrode. Thus high energy density and stability of cathode were achieved. Eco-friendly hydrothermal nanocasting was used by $\mathrm{Yu}$ et al. [98] to obtain HPC monoliths from sucrose. The template used for this purpose was hierarchically meso-macroporous silica monolith. After removing the silica template by hydrothermal treatment at $180^{\circ} \mathrm{C}$ for $6 \mathrm{~h}$, the carbon structure was soft and flexible so that the HTC chains curled up, blocked the pores and led to the low porosity. The porosity and conductivity were increased by post treatment at $950^{\circ} \mathrm{C}$, and the surface 
area and pore volume of $1426 \mathrm{~m}^{2} \mathrm{~g}^{-1}$ and $3.097 \mathrm{~cm}^{3} \mathrm{~g}^{-1}$, respectively, were attained. Due to high porosity, the S/C composite with a mass ratio of 3:1 was achieved. At $0.1 \mathrm{C}$, the composite exhibited a high initial discharge capacity of $1305 \mathrm{~mA} \mathrm{~h} \mathrm{~g}^{-1}$.

The unique characteristics of each different kind of pores in the composite have urged scientists to pursue hierarchical micro-meso-macro architectures for improved sulfur utilization. Wei et al. [100] prepared an HPC with high surface area from pig bone which was activated with $\mathrm{KOH}$. They also investigated the effect of activation temperature on the surface area and pore volume, and found that HPC exhibited the highest pore volume $\left(2.26 \mathrm{~cm}^{3} \mathrm{~g}^{-1}\right)$ and specific surface area $\left(2157 \mathrm{~m}^{2} \mathrm{~g}^{-1}\right)$ at $850^{\circ} \mathrm{C}$ (Fig. 5a). The pig-bone derived HPC showed high structural stability even at high temperatures. The HPC structure contained interconnected macro-, meso- and micro-pores, in which macro/mesopores provided appropriate ion transfer path while micropores prevented capacity fading during cycling (Fig. 5b). As an electrode with sulfur, the HPC/S composite exhibited a high initial capacity of $1265 \mathrm{~mA} \mathrm{~h} \mathrm{~g}^{-1}$. Qu et al. [101] designed a 3D hierarchically porous honeycomb carbon from glucose and colloidal silica spheres as removable templates. The honeycomb carbon possessed a surface area of $614 \mathrm{~m}^{2} \mathrm{~g}^{-1}$ with the major contribution being micropores and with a pore volume of $1.34 \mathrm{~cm}^{3} \mathrm{~g}^{-1}$. The honeycomb carbon contained internally connected macro/meso/micropores that efficiently infiltrated the sulfur, providing good electronic/ionic conductivity and suppressing the shuttle effect. The composite with 66.3 wt.\% S loading exhibited an initial discharge capacity of $923 \mathrm{~mA} \mathrm{~h} \mathrm{~g}^{-1}$. In particular, a long-term cycling stability up to 300 cycles was observed at 1.5 C. Zhang et al. [102] synthesized HPC microfiber from silk cocoon (a bio-polymer widely available in nature) by carbonization at $900^{\circ} \mathrm{C}$ assisted with $\mathrm{KOH}$ activation. The carbon microfiber possessed a very high surface area of $3243 \mathrm{~m}^{2} \mathrm{~g}^{-1}$ and large pore volume of $2.1 \mathrm{~cm}^{3} \mathrm{~g}^{-1}$ (Figs $5 \mathrm{c}$ and $\mathrm{d}$ ). The sulfur was encapsulated into the carbon microfiber and used as an electrode in the Li-S cell. From the electrochemical properties, they observed that carbon microfiber/S cathode could trap the polysulfides and boost the reutilization of sulfur due to very high surface area and electronic conductivity. The carbon microfiber/S composite with $48.4 \%$ sulfur exhibited a high initial discharge capacity of 1443 $\mathrm{mA} \mathrm{h} \mathrm{g} \mathrm{g}^{-1}$ and Columbic efficiency of up to $92 \%$ after 80 cycles (Fig. 5e).

Various HPCs derived from biomass used to prepare electrode materials for Li-S batteries are compared in Table
1. The HPCs retain the advantages of macro/meso/micropores that can efficiently encapsulate the sulfur, provide good ionic and electronic conductivity and sufficiently suppress the shuttle effect. In HPCs, micropores bring high cycle performance due to the space confinement effect and inhibit the dissolution of polysulfides. The macropores allow fast electrolyte ingress and while the mesopores give good sulfur loading and promote the electronic/ionic transport. The combined effect of all these pores makes HPC an acceptable candidate for hosting sulfur and obtaining Li-S batteries with excellent cycling stability and rate capability.

\section{Bio-derived carbon nanostructures}

Another approach to obtain high performance in Li-S battery is to encapsulate sulfur within the carbon nanostructures. Bio-template method for the synthesis of nanostructures is most attracting for the researchers of bionanotechnology, chemistry, physics and materials science field. Exploiting the diversity, sustainability and cost-effectiveness of biomass, Yao et al. [103] utilized a natural composite crab shell with a Bouligand pattern as a bio-template to fabricate hollow carbon nanofiber. Sulfur was introduced by thermal infusion to prepare the crab shell-templated carbon-sulfur composites. Crab shell template based carbon showed very interesting features such as high electrode activity due to its high surface area of nanochannels and the volume buffer capacity due to the availability of empty spaces within the nanochannels, facilitating the diffusion and fast transport of $\mathrm{Li}$ ions. The prepared cathode exhibiting a high specific capacity of $1230 \mathrm{~mA} \mathrm{~h} \mathrm{~g}^{-1}$ and $60 \%$ capacity was retained over 200 cycles. They also fabricated crab shell-templated carbon/silicon composites by chemical vapor deposition (CVD) method and obtained excellent electrochemical properties. Inspired by the fish scale structure, Tao et al. [104] designed scale-like carbon nanotiles using an inexpensive and widely available biomass kapok fibers as a carbon precursor. They synthesized scale-like kapok fiber carbon nanotiles via facile calcination $\left(700^{\circ} \mathrm{C}\right)$ and grinding procedure. As sulfur host, the scale-like carbon nanotiles displayed a very high sulfur loading (93.2 wt.\%), and the S/carbon nanotiles composite exhibited noteworthy electrochemical performance. They hypothesized that the scale-like carbon nanotiles successfully suppressed the shuttling of polysulfides, accommodated volume expansion and made the sulfur particles electrically conducting during the $\mathrm{Li}^{+}$insertion/extraction process. At $0.4 \mathrm{C}$, the composite showed a reversible capacity of $524 \mathrm{~mA} \mathrm{~h} \mathrm{~g}^{-1}$ with capacity retention of $95.4 \%$ after 


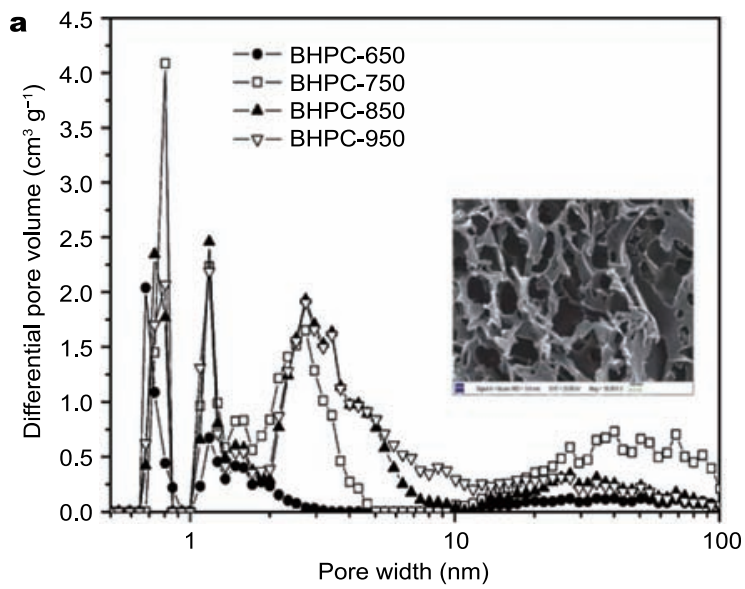

b
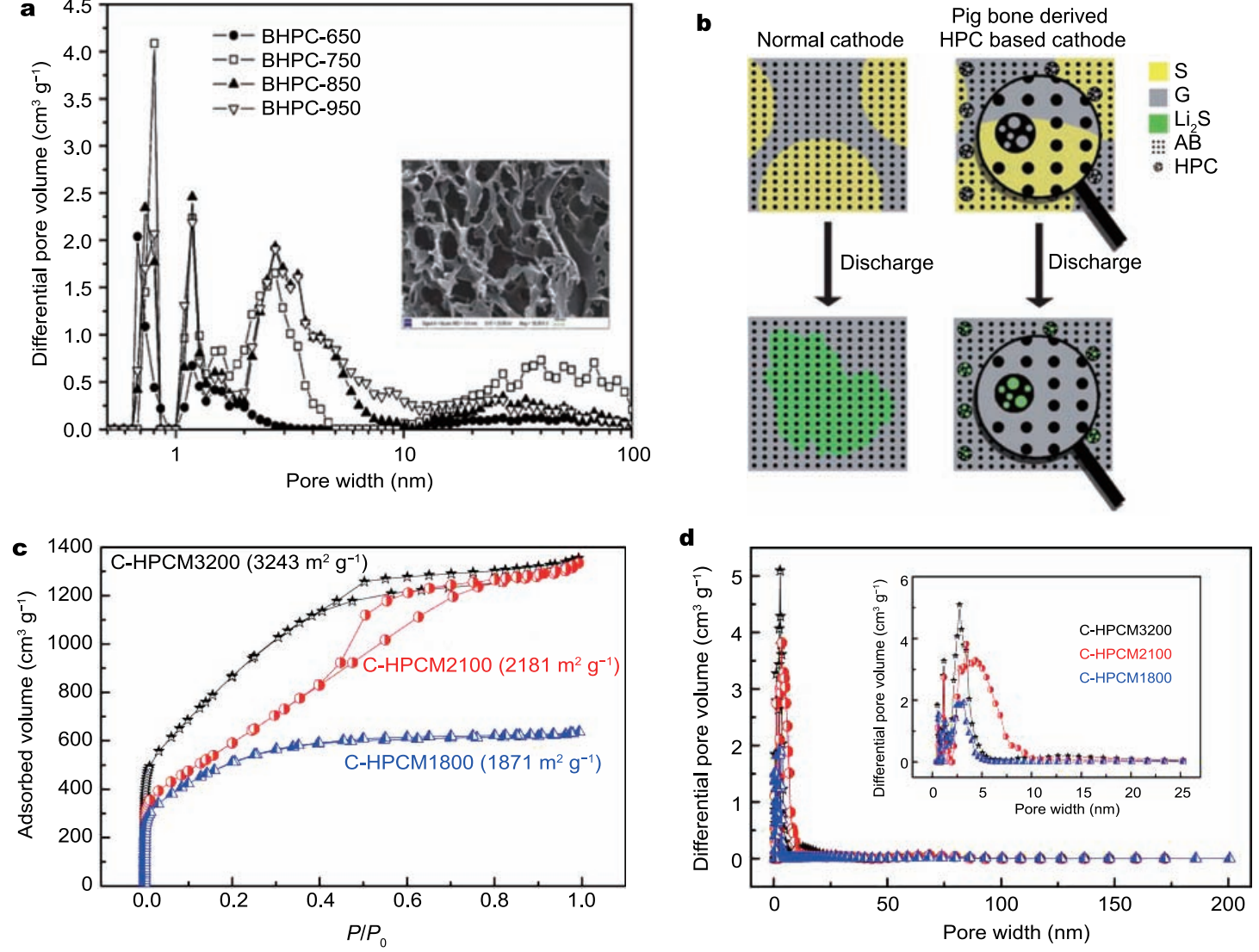

$\mathbf{e}$
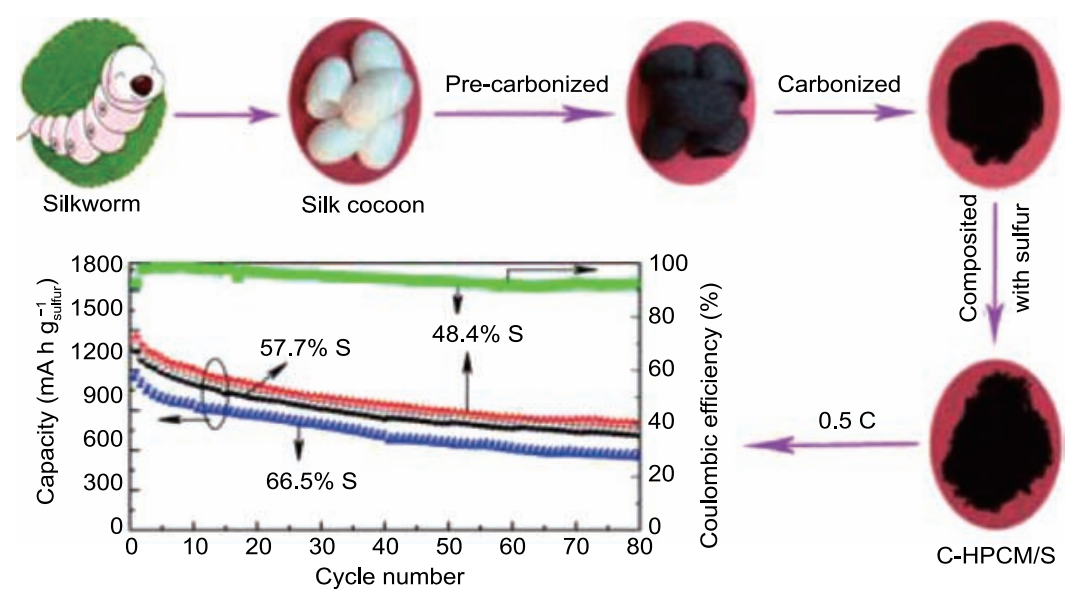

Figure 5 (a) Pore size distribution curves at different activation temperatures. The inset in (a) is a scanning electron microscopy image of the pig bone based HPC at activation temperature of $850^{\circ} \mathrm{C}$. (b) Illustration of normal cathode and pig-bone derived HPC based cathode. The AB and G represent acetylene black and gelatin (Reprinted with permission from Ref. [100], Copyright 2011, Royal Society of Chemistry). (c and d) $\mathrm{N}_{2}$ adsorption-desorption isotherms, specific surface area and pore size distribution of C/HPCMs (hierarchically porous carbon materials). (e) Schematic preparation for C/HPCMs composites and cycle performance (Reprinted with permission from Ref. [102], Copyright 2014, American Chemical Society).

90 cycles.

The dissolution of lithium polysulfides, agglomeration of insulated sulfur and corrosion of the lithium anode are some of the main reasons for the low utilization of sulfur. Yang et al. [99] combined the chemical bonding and envel- opment for high utilization of sulfur. They prepared a carbon precursor by carbonizing sucrose using concentrated $\mathrm{H}_{2} \mathrm{SO}_{4}$ and the resultant precursor was deoxygenated to obtain the carbon matrix. It was observed that the prepared carbon matrix was comprised of large lamellas. The syn- 
thesized C/S composite contained a carbon coating outside and $\mathrm{C}-\mathrm{S}$ bond which was promoted due to deoxygenation of the carbon precursor. The obtained structure showed improved electrochemical properties compared with acetylene black and sulfur composite because of the high utilization of sulfur during charge/discharge. The coating of carbon and $\mathrm{C}-\mathrm{S}$ bonding can hold the sulfur and maintain contact between the sulfur and conductive carbon.

In pursuit of a cheap and abundant carbon source to obtain the desirable morphology for rapid electron and ion transportation as sulfur host, Guo et al. [105] utilized corncob as the carbon source. They obtained a bimodal porous carbon with 2D nano-sheet structure by carbonization and activation with $\mathrm{KOH}$. The as-synthesized carbon exhibited a large surface area of $1198 \mathrm{~m}^{2} \mathrm{~g}^{-1}$ with pore volume of $0.672 \mathrm{~cm}^{3} \mathrm{~g}^{-1}$. The $\mathrm{C} / \mathrm{S}$ composite was prepared by conventional melt-diffusion technique. The $2 \mathrm{D}$ structure of carbon provided excellent pathways for electron/ion transportation and restricted polysulfides within the electrode. Due to the large surface area, high sulfur utilization was observed with the initial discharge capacity of $1600 \mathrm{~mA} \mathrm{~h} \mathrm{~g}^{-1}$ and the reversible capacity of $554 \mathrm{~mA} \mathrm{~h} \mathrm{~g}^{-1}$ after 50 cycles.

Table 2 lists the biomass-derived nanostructured carbons used as host materials in Li-S batteries. Biomass-derived nanostructured porous $\mathrm{C} / \mathrm{S}$ composites represent an excellent method for improving cathode performance in Li-S batteries, as demonstrated in the above examples. The use of bio-template instead of nano-templating provides a cheap, effective and green route to fabricate nanostructured carbons and has been proven to be effective to overcome the problems for Li-S batteries. From the reports discussed, it is obvious that rational biomass derived nanostructures are promising for addressing the numerous challenges for high-performance Li-S batteries.

According to the above mentioned examples, the pore structure of bio-derived carbon has great influence on the performance of the Li-S batteries. Microporous carbon can facilitate the immobilization of sulfur and inhibit the shuttle effect, leading to a long cycling stability. However, the limited sulfur loading and lower discharge plateau in microporous carbon/sulfur composite has dramatically reduced the capacity and the energy density of the battery, respectively. Compared with microporous carbon, mesoporous carbon has a higher sulfur loading due to its larger pore size and higher pore volume, and meanwhile the composite also shows a higher voltage plateau. Thus, mesoporous carbon/sulfur composite shows higher capacity and energy density in comparison with microporous carbon. Nevertheless, the cycling stability of mesoporous carbon should be further improved because it cannot efficiently avoid the dissolution of polysulfides. Macroporous carbon has been little reported because its large open structure results in poor inhibition of polysulfides. However, macroporous carbon permits fast electrolyte ingress and diffusion for enhanced ion-transport kinetics, and offers large volume space for high sulfur loading. As discussed, the individual porous carbon cannot satisfy all the requirements of sulfur host in Li-S batteries. Considering the unique characteristics of each kind of pores, to balance their advantages and disadvantages, the hierarchical bio-derived carbon architectures have been well developed and exhibited an optimum performance in Li-S batteries as mentioned above. In hierarchical carbon, micropores can efficiently encapsulate the sulfur, suppress the shuttle effect, and macropores and mesopores can allow fast electrolyte ingress as well as higher sulfur loading. Therefore, the use of hierarchical carbon, due to its combined effect, as a host for sulfur in Li-S batteries has been considered the best strategy.

\section{BIO-DERIVED CARBON AS INTERLAYERS IN Li-S BATTERIES}

As we know, the so-called "shuttle effect" is due to dissolution of polysulfides in the electrolyte and their free diffusion between the anode and cathode. To explore a more effective and facile strategy to inhibiting the shuttling mechanism, Manthiram's group introduced a series of papers on a new concept of inserting a carbon interlayer between the cathode and separator $[106,107]$. This interlayer carbon can block polysulfides within the electrode, enhance the utilization of the active material and further boost the conductivity. By considering the importance of bio-derived materials, Manthiram and co-workers prepared sucrose-coated chicken eggshell membrane followed by carbonization at $800^{\circ} \mathrm{C}$ [108]. The as-prepared membrane contained both micro and macropores for trapping the active mass and also functioned for continuous electron path. A sandwich electrode was fabricated in which the bottom membrane acted as a current collector and encapsulated the active mass, whereas the top membrane played the role of inhibitor. The sandwiched membrane cathode permitted the dissolved polysulfides to be localized and stabilized the electrochemical reaction. As a result, an excellent discharge capacity of $1327 \mathrm{~mA} \mathrm{~h} \mathrm{~g}^{-1}$ was achieved. The same group recently employed tree leaves to form a free-standing carbon film by carbonization at $800^{\circ} \mathrm{C}$ [109]. To maintain the natural structure, they rinsed the carbonized leaves with deionized water only and without any alkali/acid treatment. The as-prepared naturally carbonized leaves were then 
Table 2 Biomass derived nanostructured carbons and their electrochemical properties in Li-S batteries

\begin{tabular}{|c|c|c|c|c|c|c|c|c|c|c|}
\hline Biomass source & Obtained structure & Activating agent & $\begin{array}{l}\text { Surface area } \\
\left(\mathrm{m}^{2} \mathrm{~g}^{-1}\right)\end{array}$ & $\begin{array}{l}\text { Pore volume } \\
\left(\mathrm{cm}^{3} \mathrm{~g}^{-1}\right)\end{array}$ & $\begin{array}{l}\text { Initial capacity } \\
\left(\mathrm{mA} \mathrm{h} \mathrm{g}^{-1}\right)\end{array}$ & 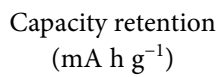 & $\begin{array}{l}\text { Cycle } \\
\text { number }\end{array}$ & Rate (C) & S (wt.\%) & Ref. \\
\hline Crab shells & Hollow carbon nanofiber & I & 1 & 1 & 1230 & 810 & 200 & 0.2 & $\sim 65$ & [103] \\
\hline Kapok fiber & Carbon nanotiles & / & 282 & 0.157 & 549 & 524 & 90 & 0.4 & 93 & [104] \\
\hline Sucrose & Lamellar carbon & $\mathrm{H}_{2} \mathrm{SO}_{4}$ & l & l & 1266 & 886 & 100 & 0.1 & 57 & [99] \\
\hline Corncob & Nanosheet microporous & $\mathrm{KOH}$ & 1198 & 0.672 & 1600 & 554 & 50 & 0.1 & 44 & [105] \\
\hline
\end{tabular}

Table 3 Summary of bio-derived carbons and their application as interlayers in Li-S batteries

\begin{tabular}{|c|c|c|c|c|c|c|c|c|c|c|}
\hline Biomass source & Obtained structure & Activating agent & $\begin{array}{l}\text { Surface area } \\
\qquad\left(\mathrm{m}^{2} \mathrm{~g}^{-1}\right)\end{array}$ & $\begin{array}{l}\text { Pore volume } \\
\qquad\left(\mathrm{cm}^{3} \mathrm{~g}^{-1}\right)\end{array}$ & $\begin{array}{l}\text { Initial capacity } \\
\quad\left(\mathrm{mA} \mathrm{h} \mathrm{g}^{-1}\right)\end{array}$ & $\begin{array}{l}\text { Capacity retention } \\
\qquad\left(\mathrm{mA} \mathrm{h} \mathrm{g}^{-1}\right)\end{array}$ & $\begin{array}{l}\text { Cycle } \\
\text { number }\end{array}$ & Rate $(\mathrm{C})$ & S (wt.\%) & Ref. \\
\hline $\begin{array}{l}\text { Natural carbonized } \\
\text { leaf }\end{array}$ & Micro/mesoporous & Interlayer & 390 & 0.34 & 1320 & 1013 & 100 & 0.1 & 70 & [109] \\
\hline Filamentous fungi & $\begin{array}{l}\text { Meso/macropores } \\
\text { carbon fiber monolith }\end{array}$ & Interlayer & 20.8 & 1.45 & $\sim 970$ & 650 & 100 & 0.5 & 60 & [111] \\
\hline Bamboo sticks & $\begin{array}{l}\text { Macro/micropore } \\
\text { structures }\end{array}$ & Interlayer & 776 & 0.33 & 907.8 & 605.7 & 300 & 1 & 70 & [112] \\
\hline Bacterial cellulose & 3D carbon nanofiber & $S$ host + interlayer & 375 & 5.29 & $\sim 1060$ & 700 & 400 & 0.24 & 81 & [113] \\
\hline Eggshell membrane & Macro/micropores & $\begin{array}{l}S \text { host + current } \\
\text { collector + interlayer }\end{array}$ & 429 & 0.36 & 1327 & 1000 & 100 & 0.1 & $3.2 \mathrm{mg} \mathrm{cm}^{-2}$ & [108] \\
\hline
\end{tabular}


used as a polysulfide inhibitor in sulfur batteries, which efficiently suppressed polysulfide shuttling due to the availability of micro-mesoporous adsorption sites and inherent moisture retention sites. The conductivity of cell was improved, and as a result, the Li-S cell showed high discharge capacity of $1320 \mathrm{~mA} \mathrm{~h} \mathrm{~g}^{-1}$, and long-term cycling stability with a discharge/charge efficiency of $98 \%$ and a low capacity fading of $0.18 \%$ per cycle.

A high yield tropical crop cassava was carbonized at $800^{\circ} \mathrm{C}$ by Qin et al. [110] to obtain cassava carbon material. The cassava-derived carbon sheet was employed as an interlayer for a Li-S battery. Such interlayer contained macroporous structure to provide accommodation and reutilization of polysulfides, and availability of active material to the electrolyte with enhanced electronic and ionic conductivity. The Li-S cell with the interlayer exhibited excellent rate performance and rate capability. A reversible capacity of $811 \mathrm{~mA} \mathrm{~h} \mathrm{~g}^{-1}$ was kept after 100 cycles at $0.5 \mathrm{C}$, and discharge capacity of $640 \mathrm{~mA} \mathrm{~h} \mathrm{~g}^{-1}$ was obtained at high rate $(4 \mathrm{C})$. Zhang et al. [111] reported the sustainable synthesis of highly porous carbon fiber monolith from filamentous fungi by filtration and subsequent pyrolysis. Fungi were cultured, followed by subsequent filtration and drying to achieve fungi aerogel. Intact carbon fiber monolith was formed via pyrolysis. Doping carbon monolith with $\mathrm{N}$ and $\mathrm{O}$ produced materials with surface areas of 305 and $20 \mathrm{~m}^{2} \mathrm{~g}^{-1}$, respectively. This carbon monolith was employed as interlayer for Li-S battery and promising electrochemical properties were attained with a capacity of $650 \mathrm{~mA} \mathrm{~h} \mathrm{~g}^{-1}$ after 100 cycles. Recently, Gu et al. [112] utilized bamboo sticks to prepare bamboo carbon fibers by treating with $\mathrm{KOH}$ solution and calcination at $800^{\circ} \mathrm{C}$. The as-synthesized carbon fibers were interwoven to form a carbon-fiber-membrane and used as an interlayer between $\mathrm{C} / \mathrm{S}$ cathode and separator. The carbon-fiber-membrane significantly suppressed the shuttle effect by retaining the polysulfides (Fig. 6a). It also provided efficient electrolyte and ion transportation along with a good conductive network. The Li-S battery with carbon-fiber-membrane showed a high sulfur loading of 70 wt.\%, a superb Columbic efficiency of $98 \%$ and a stable cyclability with capacity fading of only $0.11 \%$ per cycle (Fig. 6b).

Recently carbonized bacterial cellulose has received attention. Huang et al. [113] derived a low-cost and ecofriendly 3D carbonaceous aerogel from bacterial cellulose for Li-S batteries. With the carbonized aerogel as sulfur host, a 81 wt.\% S loading was attained. Meanwhile, the cellulose aerogel was thin enough to be directly used as an

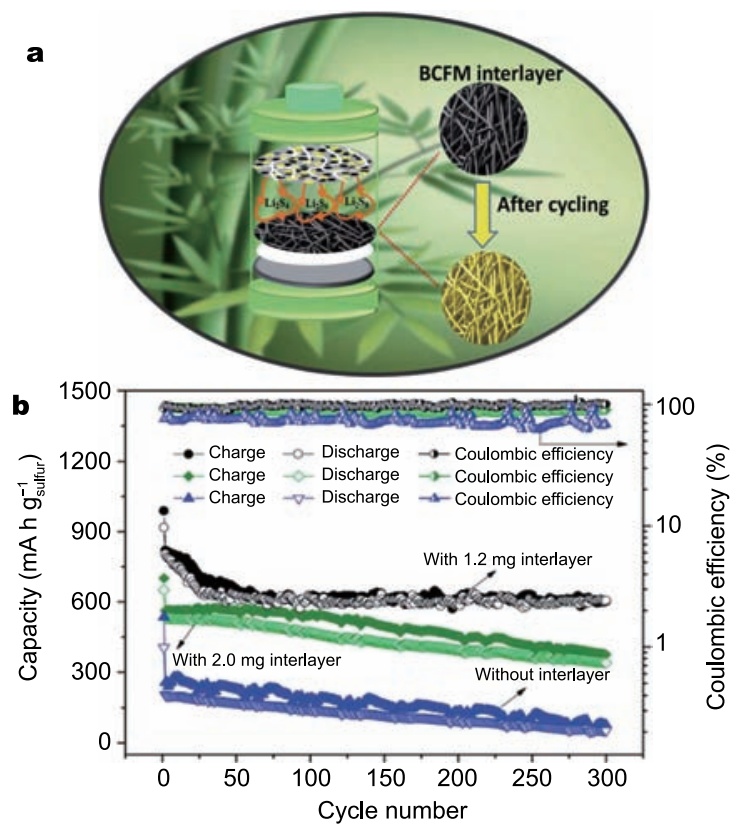

Figure 6 (a) Cell configuration with the bamboo carbon fiber membrane (BCFM) interlayer. (b) Cycle life of cells at $1 \mathrm{C}$. Reprinted with permission from Ref. [112], Copyright 2015, Royal Society of Chemistry.

interlayer. The highly interconnected nanofibrous macroporous structure of the carbonized cellulose aerogel brought structural stability and fast diffusion of Li ions through the electrolyte. A high specific capacity based on total mass of electrode can be achieved due to the binder and current collector-free cathode, while the interlayer can successfully reduce the electrode resistance and effectively adsorb the migrated polysulfides. The cell exhibited a discharge capacity as high as $1134 \mathrm{~mA} \mathrm{~h} \mathrm{~g}^{-1}$ (based on elemental sulfur) at 200 $\mathrm{mA} \mathrm{g}^{-1}$ and an average Columbic efficiency of $98.3 \%$ over 400 cycles, which should be ascribed to the combined and rational configuration of bacterial cellulose aerogel.

Table 3 summarizes bio-derived carbons and their application as interlayers in Li-S batteries. The carbon interlayer provides a high utility of active material by blocking polysulfides within the electrode system and thus gives rise to high cycling stability. Although this novel approach is very effective for high sulfur utilization, it should also be noted that the carbon interlayer is usually electrochemically inactive and affects sulfur content in a cell system, which ultimately decreases the energy density of the cell. It is proposed to reduce the weight or thickness of the interlayer though this strategy weakens its dual function [114]. Therefore, it is necessary to modify the structure of the carbon interlayer to obtain high porosity with modified pore size distribution. By using naturally available precursors, 
advanced interlayers can be obtained to maintain high energy density for Li-S batteries.

\section{CONCLUSIONS AND REMARKS}

This review is intended to provide the readers an overview of recent progress in bio-derived carbon materials used as sulfur hosts and interlayers in high-performance Li-S batteries. We highlight various preparation methods from different biomass precursors for carbons with microporous, mesoporous, hierarchical porous and some other nanostructured morphologies, and demonstrate the importance of using biomass to achieve green, cost-effective and energy efficient synthesis. Furthermore, the effects of preparation methods and microstructures of the bio-derived carbons on the electrochemical performances of $\mathrm{Li}-\mathrm{S}$ batteries have been systematically discussed. Although in the recent years substantial progresses in Li-S batteries have been made by using nanostructured porous carbons based on their novel physicochemical properties, many challenges such as cycling stability, energy density and safety are still faced for commercial application. The energy density is closely associated with the sulfur content in the cathode, the cycling stability is mainly due to the shuttling effect, and the safety is related with the $\mathrm{Li}$ anode.

It should be noted that the main advantage of Li-S batteries is their high energy density. However, additives such as binders, additional carbon black conductive and current collectors may weaken this advantage. Therefore, in order to make a practicable Li-S battery, a carbon material is needed to provide: (1) appropriate porosity for high sulfur loading, (2) excellent conductive framework, and (3) efficient utilization without binder and current collector. As discussed, the individual carbon cannot provide high loading capability as well as inhibition of polysulfides. Therefore, an optimal hierarchically porous carbon architecture containing micropores outside and meso/macropores inside could be the best choice, in which the micropores serve as polysulfides inhibitor and the meso/macropores guarantee high sulfur loading as well as fluent ion and electrolyte transport. In addition, a free-standing carbon electrode is desirable because it does not involve the binders, conductive additives and current collectors needed to achieve high sulfur loading and hence ultimately high energy density.

One of the main reasons for the shuttle effect is the sulfiphobic nature of the carbon hosts that limits them to physically adsorb polysulfides. Since the lithium polysulfides are inherently polar molecules, they do not engage in strong interactions with typical non-polar carbons. To maximize the bonding between carbon and lithium polysulfides, the sulfiphobic surface of carbon material should be functionalized to induce sulfiphilic characteristics. A new strategy is to design a sulfur host that can utilize chemisorption and thus prevent lithium polysulfides from shuttling (Fig. 7) $[71,72,115]$. The surface chemistry of carbon can be modified by functionalization by heteroatom-doping. These modified carbonaceous materials can enhance polar-polar interaction with lithium polysulfides. Thus there is a need to find a biomass source that has inherently heteroatom-doping, which can naturally enhance the chemical interactions between sulfur and carbon to meet the demands of Li-S batteries. The surface modification of C/S composite with different conductive materials, polymers and metal hydroxides such as graphene [116], polyethylene glycol [117], PEDOT:PSS [118], polyaniline [119] and $\mathrm{Ni}(\mathrm{OH})_{2}[120]$ has also been proven to be a good choice for obtaining high cycling stability since they can effectively trap the shuttling polysulfides during cycling. Therefore, the key to utilizing biomass-derived porous carbons to achieve commercially viable high energy density with improved cyclability is to develop the advanced hybrid nanostructures as described above.

We hope that this review can pave the avenues and inspire more researchers and scientists to work towards developing the next-generation biomass porous carbons to achieve low-cost, sustainable and green Li-S batteries for practical commercialization.

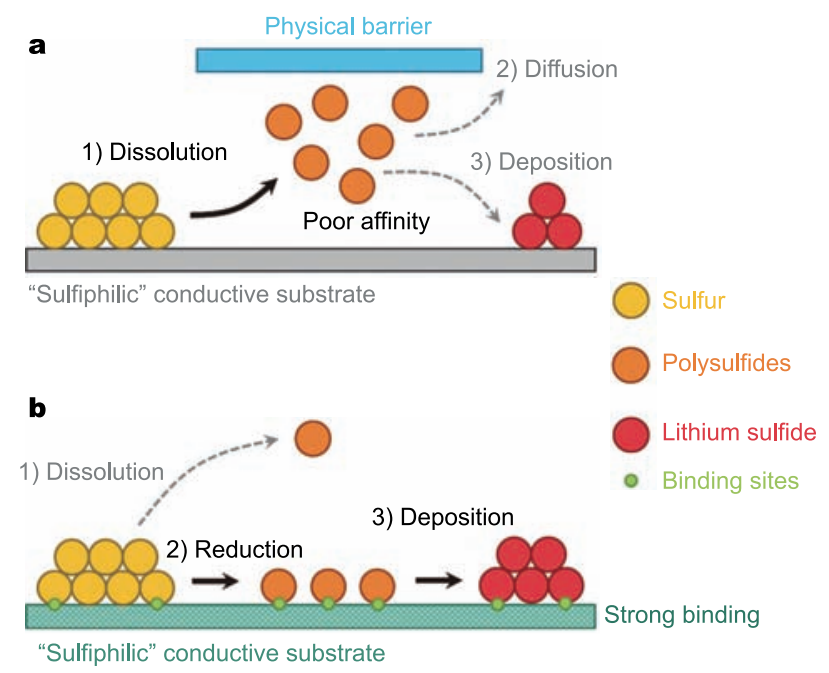

Figure 7 (a) Physical confinement of polysulfides by a sulfiphobic conductive surface (for example, carbonaceous materials); and (b) enhanced affinity of polysulfide intermediates for the surface by polar adsorbents as sulfiphilic conductive substrates (for example, $\mathrm{N}$-doped carbon materials). Reprinted with permission from Ref. [72], Copyright 2015, John Wiley and Sons. 
Received 5 April 2016; accepted 1 May 2016; published online 12 May 2016

1 Frieden E. The chemical elements of life. Sci Am, 1972, 227: 52-60

2 Ho YS, Malarvizhi R, Sulochana N. Equilibrium isotherm studies of methylene blue adsorption onto activated carbon prepared from delonix regia pods. J Environ Prot Sci, 2009, 3: 111-116

3 Idris S, Iyaka YA, Dauda BEN, et al. Kinetic study of utilizing groundnut shell as an adsorbent in removing chromium and nickel from dye effluent. Am Chem Sci J, 2012, 2: 12-24

4 Li S, Dong Y, Xu L, et al. Effect of carbon matrix dimensions on the electrochemical properties of $\mathrm{Na}_{3} \mathrm{~V}_{2}\left(\mathrm{PO}_{4}\right)_{3}$ nanograins for highperformance symmetric sodium-ion batteries. Adv Mater, 2014, 26 : 3545-3553

5 Zhu ZL, Li AM, Xia MF, et al. Preparation and characterization of polymer-based spherical activated carbons. Chin J Polym Sci, 2008, 26: 645-651

6 Candelaria SL, Cao G. Increased working voltage of hexamine-coated porous carbon for supercapacitors. Sci Bull, 2015, 60: $1587-1597$

$7 \mathrm{Hu}$ Z, Srinivasan MP. Mesoporous high-surface-area activated carbon. Micropor Mesopor Mat, 2001, 43: 267-275

8 Diasa JM, Alvim-Ferraz MCM, Almeida MF, et al. Waste materials for activated carbon preparation and its use in aqueous-phase treatment: a review. J Environ Manag, 2007, 85: 833-846

9 Mohammad-Khah A, Ansari R. Activated charcoal: preparation, characterization and applications: a review article. Int J ChemTech Res, 2009, 1: 859-864

10 Mai L, Minhas-Khan A, Tian X, et al. Synergistic interaction between redox-active electrolyte and binder-free functionalized carbon for ultrahigh supercapacitor performance. Nat Commun, 2013, 4: 2923

11 Yao Y, Wu F. Naturally derived nanostructured materials from biomass for rechargeable lithium/sodium batteries. Nano Energy, 2015, 17: 91-103

12 Ioannidou O, Zabaniotou A. Agricultural residues as precursors for activated carbon production-a review. Renew Sust Energ Rev, 2007, 11: 1966-2005

13 Chen Y, Zhu Y, Wang Z, et al. Application studies of activated carbon derived from rice husks produced by chemical-thermal process-a review. Adv Colloid Interface Sci, 2011, 163: 39-52

14 Yu M, Li R, Wu M, et al. Graphene materials for lithium-sulfur batteries. Energy Storage Mater, 2015, 1: 51-73

15 Manthiram A, Fu Y, Chung S, et al. Rechargeable lithium-sulfur batteries. Chem Rev, 2014, 114: 11751-11787

16 Massé RC, Uchaker E, Cao G. Beyond Li-ion: electrode materials for sodium- and magnesium-ion batteries. Sci China Mater, 2015, 58: 715-766

17 Liang J, Sun ZH, Li F, et al. Carbon materials for Li-S batteries: functional evolution and performance improvement. Energy Storage Mater, 2016, 2: 76-106

18 Li Z, Huang Y, Yuan L, et al. Status and prospects in sulfur-carbon composites as cathode materials for rechargeable lithium-sulfur batteries. Carbon, 2015, 92: 41-63

19 Li H, Sun L, Wang G. Self-assembly of polyethylene glycol-grafted carbon nanotube/sulfur composite with nest-like structure for highperformance lithium-sulfur batteries. ACS Appl Mater Inter, 2016, 8: 6061-6071

20 Wang JG, Xie K, Wei B. Advanced engineering of nanostructured carbons for lithium-sulfur batteries. Nano Energy, 2015, 15: 413-444

21 Yang Y, Zheng GY, Cui Y. Nanostructured sulfur cathodes. Chem
Soc Rev, 2013, 42: 3018-3032

22 Lin Z, Liang C. Lithium-sulfur batteries: from liquid to solid cells. J Mater Chem A, 2015, 3: 936-958

23 Kumaresan K, Mikhaylik Y, White RE. A mathematical model for a lithium-sulfur cell. J Electrochem Soc, 2008, 155: A576-A582

24 Peled E, Gorenshtein A, Segal M, et al. Rechargeable lithium-sulfur battery. J Power Sources, 1989, 26: 269-271

25 Mikhaylik YV, Akridge JR. Polysulfide shuttle study in the Li/S battery system. J Electrochem Soc, 2004, 151: A1969-A1976

26 Wang DW, Zeng Q, Zhou G, et al. Carbon-sulfur composites for Li-S batteries: status and prospects. J Mater Chem A, 2013, 1: 9382-9394

27 Song MK, Cairns EJ, Zhang Y. Lithium/sulfur batteries with high specific energy: old challenges and new opportunities. Nanoscale, 2013, 5: 2186-2204

28 Manthiram A, Chung SH, Zu C. Lithium-sulfur batteries: progress and prospects. Adv Mater, 2015, 27: 1980-2006

29 Kalyani P, Anitha A. Biomass carbon \& its prospects in electrochemical energy systems. Int J Hydrogen Energ, 2013, 38: 4034-4045

30 Tekin K, Karagöz S, Bektaş S. A review of hydrothermal biomass processing. Renew Sust Energ Rev, 2014, 40: 673-687

31 Kambo HS, Dutta A. A comparative review of biochar and hydrochar in terms of production, physico-chemical properties and applications. Renew Sust Energ Rev, 2015, 45: 359-378

32 Libra JA, Ro KS, Kammann C, et al. Hydrothermal carbonization of biomass residuals: a comparative review of the chemistry, processes and applications of wet and dry pyrolysis. Biofuels, 2011, 2: 71-160

33 Jain A, Balasubramanian R, Srinivasan MP. Hydrothermal conversion of biomass waste to activated carbon with high porosity: a review. Chem Eng J, 2016, 283: 789-805

34 Titirici MM, Antonietti M. Chemistry and materials options of sustainable carbon materials made by hydrothermal carbonization. Chem Soc Rev, 2010, 39: 103-116

$35 \mathrm{Hu} \mathrm{B}$, Wang $\mathrm{K}, \mathrm{Wu} \mathrm{L}$, et al. Engineering carbon materials from the hydrothermal carbonization process of biomass. Adv Mater, 2010, 22: $813-828$

36 Rillig MC, Wagner M, Salem M, et al. Material derived from hydrothermal carbonization: effects on plant growth and arbuscular mycorrhiza. Appl Soil Ecol, 2010, 45: 238-242

37 Sevilla M, Titirici MM. Hydrothermal carbonization: a greener route towards the synthesis of advanced carbon materials. Bol Grupo Español Carbón, 2012, 25: 7-17

38 Wang J, Kaskel S. KOH activation of carbon-based materials for energy storage. J Mater Chem, 2012, 22: 23710-23725

$39 \mathrm{Xu} \mathrm{B}$, Chen Y, Wei G, et al. Activated carbon with high capacitance prepared by $\mathrm{NaOH}$ activation for supercapacitors. Mater Chem Phys, 2010, 124: 504-509

40 Elmouwahidi A, Zapata-Benabithe Z, Carrasco-Marin F, et al. Activated carbons from $\mathrm{KOH}$-activation of argan (Argania spinosa) seed shells as supercapacitor electrodes. Bioresour Technol, 2012, 111: 185-190

41 Ismanto AE, Wang S, Soetaredjo FE, et al. Preparation of capacitor's electrode from cassava peel waste. Bioresour Technol, 2010, 101: 3534-3540

$42 \mathrm{Li} \mathrm{X}$, Xing W, Zhuo S, et al. Preparation of capacitor's electrode from sunflower seed shell. Bioresour Technol, 2011, 102: 1118-1123

43 Peng C, Yan XB, Wang RT, et al. Promising activated carbons derived from waste tea-leaves and their application in high performance supercapacitors electrodes. Electrochim Acta, 2013, 87: $401-408$

44 Wang $\mathrm{H}, \mathrm{Yu}$ W, Shi J, et al. Biomass derived hierarchical porous carbons as high-performance anodes for sodium-ion batteries. Electrochim Acta, 2016, 188: 103-110 
45 Yang K, Gao Q, Tan Y, et al. Biomass-derived porous carbon with micropores and small mesopores for high-performance lithium-sulfur batteries. Chem Eur J, 2016, 22: 3239-3244

46 Yuan G, Yin F, Zhao Y, et al. Corn stalk-derived activated carbon with a stacking sheet-like structure as sulfur cathode supporter for lithium/sulfur batteries. Ionics, 2015, 22: 63-69

47 Geng Z, Xiao Q, Wang D, et al. Improved electrochemical performance of biomass-derived nanoporous carbon/sulfur composites cathode for lithium-sulfur batteries by nitrogen doping. Electrochim Acta, 2016, 202: 131-139

48 Chen F, Yang J, Bai T, et al. Biomass waste-derived honeycomb-like nitrogen and oxygen dual-doped porous carbon for high performance lithium-sulfur batteries. Electrochim Acta, 2016, 192: 99-109

49 Rufford T, Hulicova-Jurcakova D, Khosla K, et al. Microstructure and electrochemical double-layer capacitance of carbon electrodes prepared by zinc chloride activation of sugar cane bagasse. J Power Sources, 2010, 195: 912-918

50 Zhang J, Gong L, Sun K, et al. Preparation of activated carbon from waste Camellia oleifera shell for supercapacitor application. J Solid State Electrochem, 2012, 16: 2179-2186

51 Rufford T, Hulicova-Jurcakova D, Zhu Z, et al. Nanoporous carbon electrode from waste coffee beans for high performance supercapacitors. Electrochem Commun, 2008, 10: 1594-1597

52 Deng $\mathrm{H}$, Zhang G, Xu X, et al. Optimization of preparation of activated carbon from cotton stalk by microwave assisted phosphoric acid-chemical activation. J Hazard Mater, 2010, 182: 217-224

53 Yagmur E, Ozmak M, Aktas Z. A novel method for production of activated carbon from waste tea by chemical activation with microwave energy. Fuel, 2008, 87: 3278-3285

54 Liu QS, Zheng T, Wang P, et al. Preparation and characterization of activated carbon from bamboo by microwave-induced phosphoric acid activation. Ind Crops Prod, 2010, 31: 233-238

55 Hasar H. Adsorption of nickel(II) from aqueous solution onto activated carbon prepared from almond husk. J Hazard Mater, 2003, 97: 49-57

56 Lozano-Castelló D, Calo J, Cazorla-Amorós D, et al. Carbon activation with $\mathrm{KOH}$ as explored by temperature programmed techniques, and the effects of hydrogen. Carbon, 2007, 45: 2529-2536

57 Otowa T, Tanibata R, Itoh M. Production and adsorption characteristics of MAXSORB: high-surface-area active carbon. Gas Sep Purif, 1993, 7: 241-245

58 Marsh H, Rodríguez-Reinoso F. Activated Carbon, Oxford: Elsevier, 2006

59 Romanos J, Beckner M, Rash T, et al. Nanospace engineering of KOH activated carbon. Nanotechnology, 2012, 23: 015401

60 Abioye AM, Ani FN. Recent development in the production of activated carbon electrodes from agricultural waste biomass for supercapacitors: a review. Renew Sust Energ Rev, 2015, 52: 1282-1293

61 Wei L, Yushin G. Nanostructured activated carbons from natura precursors for electrical double layer capacitors. Nano Energy, 2012, 1: 552-565

62 Yahya MA, Al-Qodah Z, Ngah CWZ. Agricultural bio-waste materials as potential sustainable precursors used for activated carbon production: a review. Renew Sust Energ Rev, 2015, 46: 218-235

63 Hadi P, Xu M, Ning C, et al. A critical review on preparation, characterization and utilization of sludge-derived activated carbons for wastewater treatment. Chem Eng J, 2015, 260: 895-906

64 Simon P, Gogotsi Y. Materials for electrochemical capacitors. Nat Mater, 2008, 7: 845-854

65 Nor NM, Chung LL, Teong LK, et al. Synthesis of activated carbon from lignocellulosic biomass and its applications in air pollu- tion control-a review. J Environ Chem Eng, 2013, 1: 658-666

66 Wang H, Li Z, Mitlin D. Tailoring biomass-derived carbon nanoarchitectures for high-performance supercapacitors. ChemElectroChem, 2014, 1: 332-337

$67 \mathrm{Gu} \mathrm{X}$, Wang Y, Lai C, et al. Microporous bamboo biochar for lithium-sulfur batteries. Nano Res, 2015, 8: 129-139

68 Yang K, Gao Q, Tan Y, et al. Microporous carbon derived from Apricot shell as cathode material for lithium-sulfur battery. Micropor Mesopor Mat, 2015, 204: 235-241

69 Xin S, Gu L, Zhao NH, et al. Smaller sulfur molecules promise better lithium-sulfur batteries. J Am Chem Soc, 2012, 134: 18510-18513

70 Helen M, Reddy MA, Diemant T, et al. Single step transformation of sulphur to $\mathrm{Li}_{2} \mathrm{~S}_{2} / \mathrm{Li}_{2} \mathrm{~S}$ in Li-S batteries. Sci Rep, 2015, 5: 12146

71 Pang Q, Liang X, Kwok CY, et al. Review-the importance of chemical interactions between sulfur host materials and lithium polysulfides for advanced lithium-sulfur batteries. J Electrochem Soc, 2015, 162: A2567-A2576

72 Peng HJ, Zhang Q. Designing host materials for sulfur cathodes: from physical confinement to surface chemistry. Angew Chem Int Ed, 2015, 54: 11018-11020

73 Song J, Xu T, Gordin ML, et al. Nitrogen-doped mesoporous carbon promoted chemical adsorption of sulfur and fabrication of highareal-capacity sulfur cathode with exceptional cycling stability for lithium-sulfur batteries. Adv Funct Mater, 2014, 24: 1243-1250

74 Yang CP, Yin YX, Ye H, et al. Insight into the effect of boron doping on sulfur/carbon cathode in lithium-sulfur batteries. ACS Appl Mater Inter, 2014, 6: 8789-8795

75 Peng HJ, Hou TZ, Zhang Q, et al. Strongly coupled interfaces between a heterogeneous carbon host and a sulfur-containing guest for highly stable lithium-sulfur batteries: mechanistic insight into capacity degradation. Adv Mater Inter, 2014, 1: 1400227

76 Candelaria SL, Uchaker E, Cao G. Comparison of surface and bulk nitrogen modification in highly porous carbon for enhanced supercapacitors. Sci China Mater, 2015, 58: 521-533

$77 \mathrm{Yu}$ M, Li R, Tong Y, et al. A graphene wrapped hair-derived carbon/sulfur composite for lithium-sulfur batteries. J Mater Chem A, 2015, 3: 9609-9615

78 Liang C, Dudney NJ, Howe JY. Hierarchically structured sulfur/carbon nanocomposite material for high-energy lithium battery. Chem Mater, 2009, 21: 4724-4730

79 Ji X, Lee KT, Nazar LF. A highly ordered nanostructured carbonsulphur cathode for lithium-sulphur batteries. Nat Mater, 2009, 8 : 500-506

80 Cheng JJ, Pan Y, Pan JA, et al. Sulfur/bamboo charcoal composites cathode for lithium-sulfur batteries. RSC Adv, 2015, 5: 68-74

81 Zhang Y, Zhao Y, Konarov A, et al. Effect of mesoporous carbon microtube prepared by carbonizing the poplar catkin on sulfur cathode performance in Li/S batteries. J Alloy Compd, 2015, 619: 298-302

82 Brun N, Sakaushi K, Yu L, et al. Hydrothermal carbon-based nanostructured hollow spheres as electrode materials for high-power lithium-sulfur batteries. Phys Chem Chem Phys, 2013, 15: 6080-6087

83 Brun N, Wohlgemuth SA, Osiceanu P, et al. Original design of nitrogen-doped carbon aerogels from sustainable precursors: application as metal-free oxygen reduction catalysts. Green Chem, 2013, 15: 2514-2524

84 Brun N, Sakaushi K, Eckert J, et al. Carbohydrate-derived nanoarchitectures: on a synergistic effect toward an improved performance in lithium-sulfur batteries. ACS Sust Chem Eng, 2014, 2: 126-129

85 Oschatz M, Thieme S, Borchardt L, et al. A new route for the preparation of mesoporous carbon materials with high performance in lithium-sulphur battery cathodes. Chem Commun, 2013, 49: 
5832-5834

86 Li J, Qin F, Zhang L, et al. Mesoporous carbon from biomass: onepot synthesis and application for Li-S batteries. J Mater Chem A, 2014, 2: 13916-13922

87 Wang D, Fu A, Li H, et al. Mesoporous carbon spheres with controlled porosity for high-performance lithium-sulfur batteries. J Power Sources, 2015, 285: 469-477

88 Zhang S, Zheng M, Lin Z, et al. Activated carbon with ultrahigh specific surface area synthesized from natural plant material for lithium-sulfur batteries. J Mater Chem A, 2014, 2: 15889-15896

89 Qu Y, Zhang Z, Zhang X, et al. Highly ordered nitrogen-rich mesoporous carbon derived from biomass waste for high-performance lithium-sulfur batteries. Carbon, 2015, 84: 399-408

90 Wang $\mathrm{H}$, Chen Z, Liu HK, et al. A facile synthesis approach to micromacroporous carbon from cotton and its application in the lithiumsulfur battery. RSC Adv, 2014, 4: 65074-65080

91 Zhang J, Xiang J, Dong Z, et al. Biomass derived activated carbon with $3 \mathrm{D}$ connected architecture for rechargeable lithium-sulfur batteries. Electrochim Acta, 2014, 116: 146-151

92 Caballero A, Hernán L, Morales J, et al. Suppressing irreversible capacity in low cost disordered carbons for Li-ion batteries. Electrochem Solid-State Lett, 2009, 12: A167-A170

93 Moreno N, Caballero A, Hernán L, et al. Lithium-sulfur batteries with activated carbons derived from olive stones. Carbon, 2014, 70: 241-248

94 Caballero A, Hernan L, Morales J. Limitations of disordered carbons obtained from biomass as anodes for real lithium-ion batteries. ChemSusChem, 2011, 4: 658-663

95 Liu M, Chen Y, Chen K, et al. Biomass-derived activated carbon for rechargeable lithium-sulfur batteries. BioResources, 2015, 10: 155-168

96 Zhao S, Li C, Wang W, et al. A novel porous nanocomposite of sulfur/carbon obtained from fish scales for lithium-sulfur batteries. J Mater Chem A, 2013, 1: 3334-3339

97 Park MS, Yu JS, Kim KJ, et al. Porous carbon spheres as a functional conducting framework for use in lithium-sulfur batteries. RSC Adv, 2013, 3: 11774-11781

98 Yu L, Brun N, Sakaushi K, et al. Hydrothermal nanocasting: synthesis of hierarchically porous carbon monoliths and their application in lithium-sulfur batteries. Carbon, 2013, 61: 245-253

99 Yang XB, Zhu W, Qin K, et al. Preparation of lamellar carbon matrix for sulfur as cathode material of lithium-sulfur batteries. Electrochim Acta, 2014, 143: 374-382

100 Wei S, Zhang H, Huang Y, et al. Pig bone derived hierarchical porous carbon and its enhanced cycling performance of lithium-sulfur batteries. Energy Environ Sci, 2011, 4: 736-740

101 Qu Y, Zhang Z, Zhang X, et al. Synthesis of hierarchical porous honeycomb carbon for lithium-sulfur battery cathode with high rate capability and long cycling stability. Electrochim Acta, 2014, 137: 439-446

102 Zhang B, Xiao M, Wang S, et al. Novel hierarchically porous carbon materials obtained from natural biopolymer as host matrixes for lithium-sulfur battery applications. ACS Appl Mater Inter, 2014, 6: 13174-13182

103 Yao H, Zheng G, Li W, et al. Crab shells as sustainable templates from nature for nanostructured battery electrodes. Nano Lett, 2013 , 13: 3385-3390

104 Tao X, Zhang J, Xia Y, et al. Bio-inspired fabrication of carbon nanotiles for high performance cathode of Li-S batteries. J Mater Chem A, 2014, 2: 2290-2296

105 Guo J, Zhang J, Jiang F, et al. Microporous carbon nanosheets derived from corncobs for lithium-sulfur batteries. Electrochim Acta,
2015, 176: 853-860

106 Su YS, Manthiram A. Lithium-sulphur batteries with a microporous carbon paper as a bifunctional interlayer. Nat Commun, 2012, 3: 1166

107 Su YS, Manthiram A. A new approach to improve cycle performance of rechargeable lithium-sulfur batteries by inserting a free-standing MWCNT interlayer. Chem Commun, 2012, 48: 8817-8819

108 Chung SH, Manthiram A. Carbonized eggshell membrane as a natural polysulfide reservoir for highly reversible Li-S batteries. Adv Mater, 2014, 26: 1360-1365

109 Chung SH, Manthiram A. A natural carbonized leaf as polysulfide diffusion inhibitor for high-performance lithium-sulfur battery cells. ChemSusChem, 2014, 7: 1655-1661

110 Qin F, Zhang K, Fang J, et al. High performance lithium sulfur batteries with a cassava-derived carbon sheet as a polysulfides inhibitor. New J Chem, 2014, 38: 4549-4554

111 Zhang L, Wang Y, Peng B, et al. Preparation of a macroscopic, robust carbon-fiber monolith from filamentous fungi and its application in Li-S batteries. Green Chem, 2014, 16: 3926-3934

$112 \mathrm{Gu}$ X, Lai C, Liu F, et al. A conductive interwoven bamboo carbon fiber membrane for Li-S batteries. J Mater Chem A, 2015, 3 : 9502-9509

113 Huang Y, Zheng M, Lin Z, et al. Flexible cathodes and multifunctional interlayers based on carbonized bacterial cellulose for high-performance lithium-sulfur batteries. J Mater Chem A, 2015, 3: 10910-10918

114 Wang J, Yang Y, Kang F. Porous carbon nanofiber paper as an effective interlayer for high-performance lithium-sulfur batteries. Electrochim Acta, 2015, 168: 271-276

115 Liang X, Garsuch A, Nazar LF. Sulfur cathodes based on conductive MXene nanosheets for high-performance lithium-sulfur batteries. Angew Chem Int Ed, 2015, 54: 3907-3911

116 Li W, Zheng G, Yang Y, et al. High-performance hollow sulfur nanostructured battery cathode through a scalable, room temperature, one-step, bottom-up approach. Proc Natl Acad Sci USA, 2013, 110: 7148-7153

117 Li Z, Yuan L, Yi Z, et al. A dual coaxial nanocable sulfur composite for high-rate lithium-sulfur batteries. Nanoscale, 2014, 6 : 1653-1660

118 Yang Y, Yu G, Cha J, et al. Improving the performance of lithiumsulfur batteries by conductive polymer coating. ACS Nano, 2011, 5: 9187-9193

119 Li GC, Li GR, Ye SH, et al. A polyaniline-coated sulfur/carbon composite with an enhanced high-rate capability as a cathode material for lithium/sulfur batteries. Adv Energy Mater, 2012, 2: 1238-1245

120 Niu XQ, Wang XL, Xie D, et al. Nickel hydroxide-modified sulfur/carbon composite as a high-performance cathode material for lithium sulfur battery. ACS Appl Mater Inter, 2015, 7: 16715-16722

Acknowledgments This work was supported by the National Natural Science Foundation of China (21477046, 21277060 and 51361130151), Science Development Project of Shandong Province (2014GGX104004) and Natural Science Foundation of Shandong Province (ZR2015EM044).

Author contributions Imtiaz $S$ and Zhang J conceived the study and wrote the manuscript. Zafar ZA, Ji S, Huang T, Anderson JA, Zhang Z and Huang $\mathrm{Y}$ modified the manuscript. All authors discussed on the manuscripts structure, arguments and conclusions.

Conflict of interest The authors declare that they have no conflict of interest. 


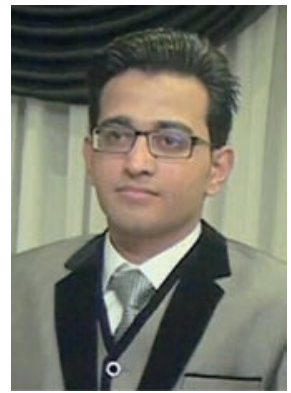

Sumair Imtiaz received his Bachelor's degree from the Department of Chemical Engineering at University of Gujrat, Pakistan in 2012. As a recipient of Chinese Government Scholarship, he is currently a graduate student in chemical engineering and technology at the University of Jinan. His research focuses on the advanced electrode materials for Li-S batteries.

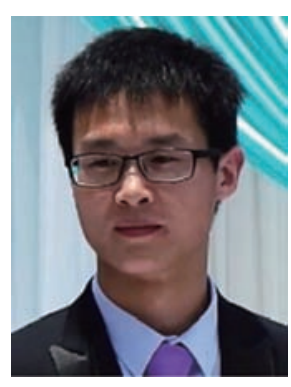

Jian Zhang received his $\mathrm{PhD}$ at Wuhan University of Technology in 2015. He is now a post-doctoral researcher at the Department of Materials Science and Engineering, Huazhong University of Science and Technology. His research mainly focuses on design and synthesis of porous carbon-based materials for low temperature fuel cells and lithium-sulfur batteries.

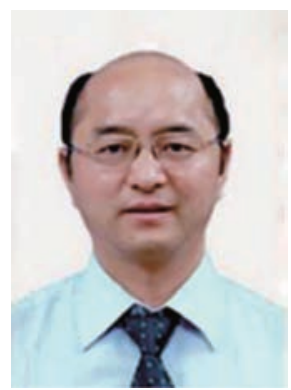

Yunhui Huang received his BSc, MSc and PhD degrees from Peking University. In 2000, he worked as a postdoctoral researcher in Peking University. From 2002 to 2004, he worked as an associate professor in Fudan University and a JSPS fellow at Tokyo Institute of Technology, Japan. He then worked in the University of Texas at Austin for more than three years. In 2008, he became a chair professor of materials science in Huazhong University of Science and Technology. He is now the dean of the School of Materials Science and Engineering. His research group works on batteries of energy storage and conversion. For details please see the lab website: http://www.sysdoing.com.cn.

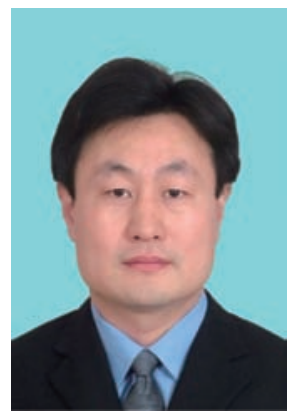

Zhaoliang Zhang received his BSc, MSc and PhD degrees from Hunan University, Shandong University and Peking University, respectively. In 2000-2001, he worked as a postdoctoral researcher in Korea Advanced Institute of Science \& Technology (KAIST), South Korea. Then he worked as a general engineer in an automobile exhaust purification corporation. In 2003, he became a professor at the School of Chemistry and Chemical Engineering, University of Jinan, China. His research group works on environmental catalysis and new materials in catalysis and energy storage and conversion.

\section{源自于生物质的纳米多孔炭在锂硫电池中的应用 \\ Sumair Imtiaz ${ }^{1 \dagger}$, 张建 ${ }^{2 \dagger}$, Zahid Ali Zafar ${ }^{1}$, 季胜楠 ${ }^{1}$, 黄太仲 ${ }^{1}$, James A. Anderson ${ }^{3}$, 张昭 ${ }^{1^{1 *}}{ }^{{ }^{*}}$ 黄云辉 $^{2^{*}}$}

摘要 在人类发展的几千年中, 生物质材料被广泛应用于能源领域, 例如木材和木炭. 基于生物质材料便宜、来源广泛、可持续发展的优 点, 采用先进的科学技术将生物质材料转换为功能化的纳米多孔碳材料, 并将其作为锂硫电池的正极材料和隔膜展现出了非常好的应用前 景. 因此, 本综述介绍了以生物质为原料制备的纳米多孔碳材料及其在锂硫电池中的应用, 并针对不同方法制备的生物质纳米多孔炭材料 的孔结构(包括微孔、介孔及分级孔)及其作为正极材料对于锂硫电池性能的影响进行了全面的总结, 这对合理利用生物质制备纳米多孔 碳材料进一步提升锂硫电池的性能具有很好的指导作用. 最后, 本文指出了当前锂硫电池的问题及挑战, 并对进一步提升锂硫电池性能提 供了有价值的观点和策略. 